\title{
Cisplatin nephrotoxicity as a model of chronic kidney disease
}

\author{
Mingjun Shi ${ }^{1} \cdot$ Kathryn L. McMillan ${ }^{1} \cdot$ Junxia $\mathrm{Wu}^{1} \cdot$ Nancy Gillings ${ }^{1} \cdot$ Brianna Flores $^{1} \cdot$ Orson W. Moe $^{1,2,3}$. \\ Ming Chang $\mathrm{Hu} \mathbb{1}^{1,2}$
}

Received: 7 December 2017 / Revised: 13 March 2018 / Accepted: 29 March 2018 / Published online: 1 June 2018

(c) United States \& Canadian Academy of Pathology 2018

\begin{abstract}
Cisplatin (CP)-induced nephrotoxicity is widely accepted as a model for acute kidney injury (AKI). Although cisplatininduced chronic kidney disease (CKD) in rodent has been reported, the role of phosphate in the cisplatin-induced CKD progression is not described. In this study, we gave a single peritoneal injection of CP followed by high (2\%) phosphate diet for 20 weeks. High dose CP $(20 \mathrm{mg} / \mathrm{Kg})$ led to high mortality; whereas a lower dose $(10 \mathrm{mg} / \mathrm{Kg})$ resulted in a full spectrum of AKI with tubular necrosis, azotemia, and $0 \%$ mortality 7 days after $\mathrm{CP}$ injection. After consuming a high phosphate diet, mice developed CKD characterized by low creatinine clearance, interstitial fibrosis, hyperphosphatemia, high plasma PTH and FGF23, low plasma $1,25(\mathrm{OH})_{2}$ Vitamin $\mathrm{D}_{3}$ and $\alpha \mathrm{Klotho}$, and classic uremic cardiovasculopathy. The CP model was robust in demonstrating the effect of aging, sexual dimorphism, and dietary phosphate on AKI and also AKI-to-CKD progression. Finally, we used the CP-high phosphate model to examine previously validated methods of genetically manipulated high $\alpha$ Klotho and therapy using exogenous soluble $\alpha$ Klotho protein supplementation. In this CP CKD model, $\alpha$ Klotho mitigated CKD progression, improved mineral homeostasis, and ameliorated cardiovascular disease. Taken together, CP and high phosphate nephrotoxicity is a reproducible and technically very simple model for the study of AKI, AKI-to-CKD progression, extrarenal complications of CKD, and for evaluation of therapeutic efficacy.
\end{abstract}

\section{Introduction}

Acute kidney injury (AKI) is a serious public health problem. Using the Kidney Disease Improving Global Outcomes (KDIGO) criteria and staging system, global incidence of AKI in hospitalized patients is $22 \%$ in adults and $34 \%$ in children [1-3]. In hospitalized patients, AKIassociated mortality rates are $24 \%$ in adults and $14 \%$ in children [2]. In intensive care unit, the incidence of AKI is

Electronic supplementary material The online version of this article (https://doi.org/10.1038/s41374-018-0063-2) contains supplementary material, which is available to authorized users.

$\triangle$ Ming Chang Hu, M.D.; Ph.D.

ming-chang.hu@utsouthwestern.edu

1 Charles and Jane Pak Center for Mineral Metabolism and Clinical Research, University of Texas Southwestern Medical Center, Dallas, TX, USA

2 Departments of Internal Medicine, University of Texas Southwestern Medical Center, Dallas, TX, USA

3 Physiology, University of Texas Southwestern Medical Center, Dallas, TX, USA
50-70\% with greater than 50\% mortality [4]. A populationbased study showed full renal recovery after AKI based on serum creatinine to be $\sim 68 \%$ [5]. Even when patients survive AKI, the long-term outcome is far from benign with substantial risk of progression to chronic kidney disease (CKD) and end-stage renal disease [6, 7]. Thus far, the precise risk of AKI-to-CKD progression is not yet well known [1], but the hazard ratio of developing CKD postAKI is estimated to be about two-fold [7]. Although there is increasing evidence from both animal experiments and clinical observations indicating that $\mathrm{AKI}$ is an independent risk for $\mathrm{CKD}$, effective retardation of AKI-to-CKD progression is not available, mainly due to lack of understanding of the pathogenic mechanism underlying AKI-toCKD progression. An animal model of AKI-to-CKD that permits pre-clinical study is indispensable.

Some rodent models of AKI-to-CKD progression have been generated by either kidney mass ablation surgery, induction of ischemia-reperfusion, or exposure to nephrotoxins. Ischemia-reperfusion by temporally clamping the renal artery or pedicle is one model widely used for studying the molecular and cellular mechanisms of AKI-toCKD progression. We recently reported that mice undergoing either bilateral IRI or unilateral nephrectomy plus 
contralateral IRI followed by high $(2 \%)$ phosphate diet develop CKD with azotemia, hyperphosphatemia, low plasma, $\alpha$ Klotho and 1,25- $(\mathrm{OH})_{2}$-vitamin $\mathrm{D}_{3}$, high plasma PTH, phosphate and fibroblast growth factor (FGF)23, renal fibrosis, vascular calcification, and uremic cardiomyopathy [8-11]. However, preparation of IRI requires rather complex animal surgery and this model cannot mimic nephrotoxic injuries, which is the second most common cause of AKI in both children and adults $[1,12]$.

Cisplatin (CP) nephrotoxicity is a severe renal complication in patients receiving CP-based chemotherapy, but the incidence of AKI following CP chemotherapy is not well defined in humans. Recent studies showed that AKI occurs in $21-31.5 \%$ of patients receiving CP-containing chemotherapy $[13,14]$. Acute CP nephrotoxicity has been used as an AKI model to study pathogenesis of AKI and to test new therapeutic options [15]. In contrast, the description of acute CP nephrotoxicity progression to CKD in rodent models is relatively limited without consensus protocols [16-21], and effect of high Pi on the CKD progression from acute CP nephrotoxicity is not reported yet.

In this manuscript, we describe a technically simple model for AKI followed by AKI-to-CKD transition in rodents. Acute nephrotoxicity is induced by single bolus injection of CP without the need for surgery, such as IRI, partial nephrectomy, or unilateral ureteral obstruction. After recovery from AKI, chronic high dietary phosphate promotes CKD progression with extrarenal complications with clinical relevance, such as mineral and bone disorder (CKD-MBD) and uremic cardiovasculopathy.

\section{Materials and methods}

\section{Rodent}

All animal work was conducted strictly following the guide for the care and use of laboratory animals by the National Institutes of Health and was approved by the institutional animal care and use committee at the University of Texas Southwestern Medical Center. Wild type (WT) 129 S1/SVlmJ (129 SV) mice were purchased from Jackson laboratory (Bar Harbor ME, USA) and Spraque-Dawley (SD) rats from Charles River Laboratories (San Diego, CA). Mice and rats were housed in a temperature-controlled room with a 12:12 h light-dark cycle and were given ad libitum access to tap water and standard rodent chow prior to the experiment. Equal male and female animals were used. Usually 3-months-old mice and 2-months-old rats were used unless specifically indicated. The heterozygous Klotho hypomorphic $(k l /+)$ mice and transgenic Klotho overexpressing $(T g-K l)$ mice were cross-mated with WT $129 \mathrm{SV}$ mice for more than 10 generations and genotyped with standard PCR protocol described previously $[8,10,11,22]$.

\section{CP nephrotoxicity and high phosphate diet}

CP (Sigma-Aldrich St. Louis, MO) was dissolved in sterile $0.9 \% \mathrm{NaCl}$, and intraperitoneally injected once. For evaluation of AKI and acute mortality, 30 mice (15 female:15 male mice) were randomized into three groups: vehicle $(0.9 \% \mathrm{NaCl})$, low dose $(10 \mathrm{mg} / \mathrm{Kg})$, and high dose $(20 \mathrm{mg} / \mathrm{Kg})$ CP. After injection, mice were allowed free access to standard rodent chow (Teklad 2016, Harlan, Madison, WI) and tap water unless stated otherwise.

For the study of AKI-to-CKD progression, $\mathrm{CP}$ was given only with low dose $(10 \mathrm{mg} / \mathrm{Kg})$, as high-dose $(20 \mathrm{mg} / \mathrm{Kg})$ $\mathrm{CP}$-injected mice could not survive more than one month. When started with 10 mice, we typically had $\sim 8$ mice at 20 weeks after CP $10 \mathrm{mg} / \mathrm{Kg}$ injection.

To promote AKI-to-CKD progression, two weeks after vehicle or CP injection, mice were switched from normal rodent chow to $2.0 \%$ (w:w) phosphate diet (Teklad 08020, Harlan, Madison, WI) for another 18 weeks.

\section{Recombinant aKlotho protein supplementation}

Soluble $\alpha$ Klotho protein containing the ectodomain of mouse $\alpha$ Klotho (amino acid number 31-982) with Cterminal V5 and 6xHis tags was generated and purified in our laboratory in mammalian cells as described previously $[11,22,23]$. For the experiment of $\alpha$ Klotho administration in CP-treated mice, CP nephrotoxicity was induced with low dose $(10 \mathrm{mg} / \mathrm{kg})$ or vehicle [24] and high phosphate (2\%) diet was given 2 weeks after CP injection [8-10]. At 4 weeks after injection, recombinant $\alpha$ Klotho protein $(0.3$ $\mathrm{mg} / \mathrm{kg}$ body weight/month) or vehicle (normal saline) was given for 16 weeks via ALZET 1004 osmotic minipumps (DURECT Corporation, Cupertino, CA). The effective lifespan for this type of minipump is 4 weeks and a new one was implanted to replace every 4 weeks resulting in 4 minipumps per animal [11]. There were 10 mice (equal male and female) at the beginning and $\sim 8$ mice at 20 weeks after $\mathrm{CP}$ injection.

\section{Blood, urine, and kidney samples collection}

At predetermined times post-AKI, 24-h urine was collected in individual metabolic cage. Mice were then anesthetized with Isoflurane and blood were collected in heparinized tubes, centrifuged at $3000 \times g$ for $5 \mathrm{~min}$ at $4{ }^{\circ} \mathrm{C}$, and plasma was separated and stored at $-80^{\circ} \mathrm{C}$ until analysis. At termination, mice were sacrificed under anesthesia, and the kidneys were isolated and sliced. One slice was fixed with 
4\% paraformaldehyde and embedded in paraffin block for histological and immunohistological studies; the remaining renal tissue were snap-frozen in liquid $\mathrm{N}_{2}$ and stored at -80 ${ }^{\circ} \mathrm{C}$ until RNA or protein extraction.

Plasma and urine chemistry were analyzed by a Vitros Chemistry Analyzer (Ortho-Clinical Diagnosis, Rochester, NY). Plasma and urine creatinine concentrations were measured using a P/ACE MDQ Capillary Electrophoresis System and photodiode detector (Beckman-Coulter, Fullerton, CA) at $214 \mathrm{~nm} \mathrm{[10].}$

\section{Measurement of plasma aKlotho, full-length FGF23, PTH, and 1,25-dihydroxyvitamin $D_{3}$}

$\alpha$ Klotho was determined by immunoprecipitationimmunoblot as described [9, 10, 25]. Intact PTH was quantified by ELIZA (Alpco, Salem, $\mathrm{NH}) ; 1,25-(\mathrm{OH})_{2}$ vitamin $\mathrm{D}_{3}$ by EIA using (Immunodiagnostic Systems, Scottsdale, AZ); and Intact FGF23 by ELIZA (Kainos, Japan) following manufactures' instructions.

\section{Antibodies}

The following antibodies were used for immunoblotting and/or immunohistochemistry (IHC): rat monoclonal anti$\alpha$ Klotho antibody (KM2076) (TransGenics, Kobe, Japan), mouse polyclonal antibody against connective tissue growth factor (CTGF) (Abcam Inc., Cambridge, MA), mouse monoclonal antibody against $\beta$-actin (Sigma-Aldrich, St. Louis, MO), mouse monoclonal antibody against $\alpha$-smooth muscle actin ( $\alpha$-SMA) (Sigma-Aldrich, St. Louis, $\mathrm{MO}$ ), and goat polyclonal antibody against neutrophil gelatinase-associated lipocalin-2 (NGAL) (R\&D Systems Inc., Minneapolis, MN). Secondary antibodies coupled to horseradish peroxidase for immunoblotting, or to FITC, Alexa Fluor, and Syto 61 infrared fluorescent nuclear acid, as well as wheat germ agglutinin (WGA) conjugated to Alexa Fluor 555 for IHC were purchased from Molecular Probes/Invitrogen (Molecular Probes Inc., Eugene, OR).

\section{Kidney histology and histopathology}

Kidney tissues were fixed in $4 \%$ paraformaldehyde for $16 \mathrm{~h}$ at $4{ }^{\circ} \mathrm{C}$, and $4 \mu \mathrm{m}$ sections of paraffin embedded kidney tissues were stained with Hematoxylin and Eosin (HE), Trichrome (TC), and Picrosirius red (PSR). Kidney histology was examined and photographed by a histopathologist blinded to the experimental protocols. We used a semi-quantitative pathological score systems for the evaluation of chronic kidney histologic damage based on the literature with minor modification $[1,2,22,24,26]$. The images were reviewed for four types of changes: glomeruli (sclerosis, dilated, or collapsing Bowman's space), tubulointerstitial fibrosis, chronic inflammatory cells infiltration, and renal tubules (necrosis, casts, or atrophy) at $\times 40$ magnification on HE-stained kidney sections. Each item was scored from 0 to 4 based on percentage involvement $(<25,25-50,50>75$, or $>75 \%$ respectively). Therefore, there might be 16 at maximum in each field. We randomly examined 10 fields at $\times 40$, and the final score will be from 0 to 160 .

To evaluate renal fibrosis, $4 \mu \mathrm{m}$ paraffin-embedded kidney sections were stained with TC and PSR, examined, and photographed by a histopathologist blinded to the experimental protocol. Renal fibrosis score is expressed in arbitrary units, and reflects both fibrotic area and severity of fibrosis in PSR-stained sections, which were quantified with Image $\mathbf{J}$ software with published methods $[8,10,11,27]$. If the photo micrograph contains glomeruli, we removed it manually with Image $\mathbf{J}$ software. Tubulointerstitial fibrosis is, hereinafter, simply referred as for renal fibrosis.

\section{Immunohistochemistry and immunoblotting in the kidney}

Four-micrometers sections of paraffin-embedded kidney were subjected to IHC with established protocols $[8,10$, $11,27]$. Total kidney lysate covering all kidney zones was prepared as described $[8,10,11,27]$. Thirty-micrograms protein of kidney lysate was solubilized in Laemmli's sample buffer and subjected to SDS-PAGE. After transferring to PVDF membranes, proteins were immunoblotted with different primary antibodies and $\beta$-actin for loading control. Signal was visualized using the ECL kit (PerkinElmer LAS, Inc., Boston, MA).

\section{Assessment of cardiac fibrosis and hypertrophy}

Paraffin-embedded heart sections were stained with TC to assess fibrosis. Images were scanned with Zeiss laser confocal scanning microscope (Carl Zeiss Micro-Imaging, Inc., Thornwood, NY), and analyzed using the Image J program $[10,11,28]$. Cardiac fibrosis score is also expressed in arbitrary unit, which reflects both fibrotic area and severity of fibrosis in TC-stained heart sections. To measure the surface area of cardiomyocytes, cardiomycte membranes in heart sections were labeled with Alexa Fluor 555conjugated to WGA (Invitrogen, Carlsbad, CA) as described $[10,11]$. Immunofluorescent images were taken on a Zeiss laser confocal scanning microscope (Carl Zeiss Micro-Imaging, Inc., Thornwood, NY). Image J software was used to quantify cross-sectional cell surface area along the mid-chamber free wall based on WGA-positive staining $[10,11]$. 
A.

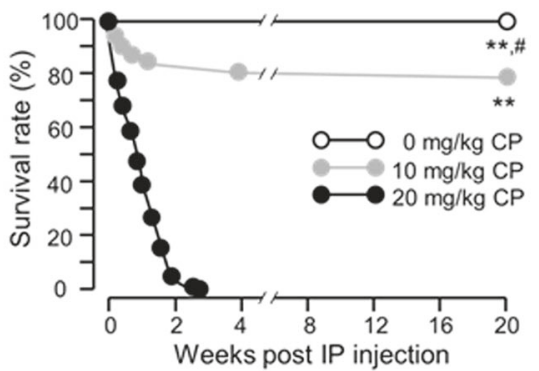

C.

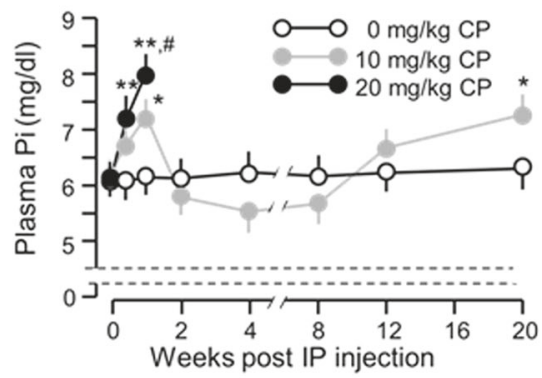

E.

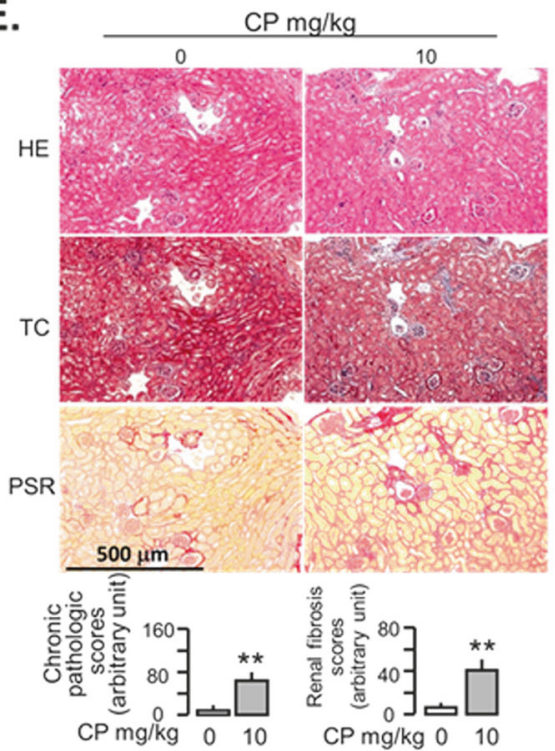

H.

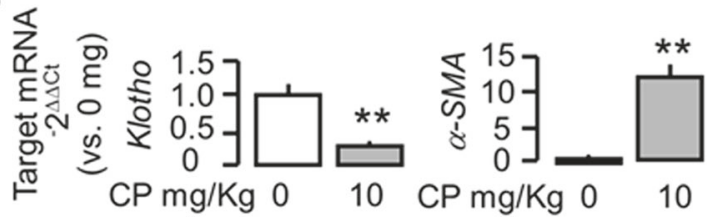

B.

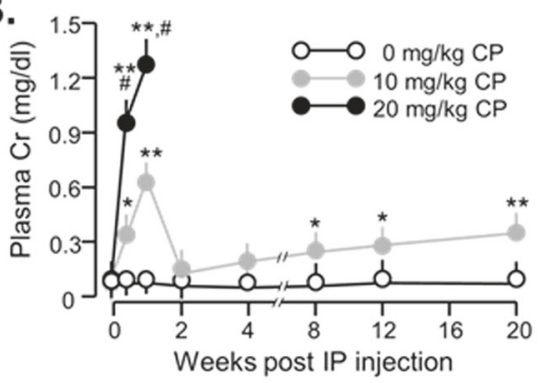

D.

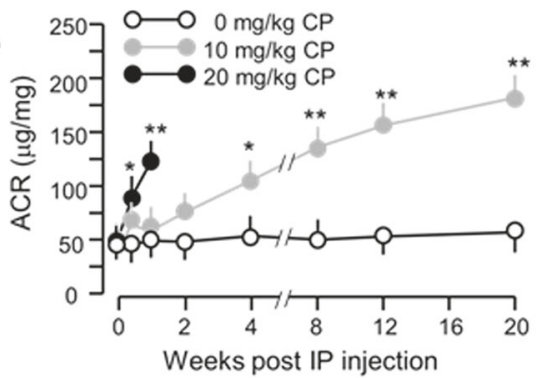

F.

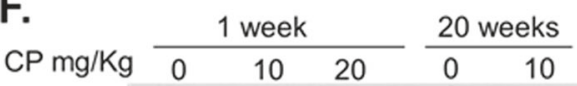

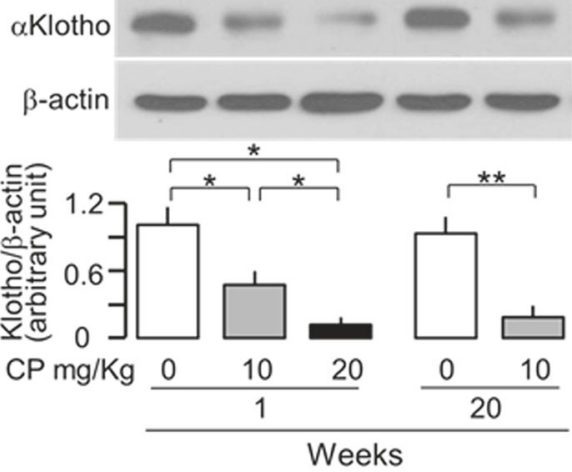

G.

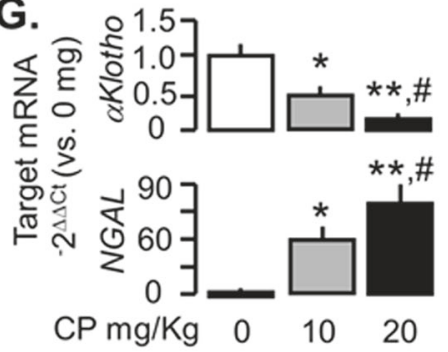

\section{Von Kossa staining and calcium concentration measurement}

The aorta was stained for calcification with Von Kossa [9]. Tissue sections were incubated with $1 \%$ silver nitrate solution under ultraviolet light for $30 \mathrm{~min}$ followed by incubation with $5 \%$ sodium thiosulfate for $10 \mathrm{~min}$ to remove the unreacted silver. Aortic sections were counterstained with nuclear fast red, photographed blindly by two investigators using Axioplan 2 Imaging (Carl Zeiss MicroImaging, Inc., Thornwood, NY). The calcium content in thoracic aortas was measured using the o-cresolphthalein complexone method (Sigma-Aldrich, St. Louis, MO) [9], which was quantified by normalized concentration to 
Fig. 1 Dose dependent cisplatin (CP)-induced kidney injury and mortality in $W T$ mice. $129 \mathrm{sv} W T$ mice were intraperitoneally injected once with $0,10,20 \mathrm{mg} / \mathrm{Kg} \mathrm{CP}$ and followed for up to 20 weeks after the injection. a Survival rate. b Plasma Cr. c Plasma Pi. d ACR. e Kidney histology assessed by HE, TC, and PSR staining (scale bar = $500 \mu \mathrm{m}$ ); and semi-quantitative assessment (bottom panel including chronic pathologic score based on HE stain and renal fibrosis score based on PSR stain). f Representative immunoblots for $\alpha$ Klotho protein in total kidney lysates (upper panel). Summary of all immunoblots (bottom panel). $\mathbf{g} \alpha$ Klotho and NGAL mRNA expression in kidney lysates at one week after $\mathrm{CP}$ injection. Transcripts in the kidneys were analyzed with $\mathrm{qPCR}$ and results are expressed as $2^{-\Delta \Delta \mathrm{Ct}}(\mathrm{Ct}=$ cycle number) by normalization to cyclophilin and compared to the $0 \mathrm{mg} / \mathrm{Kg}$ group. Data are expressed as means \pm SD from each group and statistical significance was evaluated by one-way ANOVA followed by Student-Newman-Keuls post hoc test, and significance was accepted when $* P<0.05$; $* * P<0.01$ vs. $0 \mathrm{mg} / \mathrm{Kg},{ }^{\#} P<0.05$ vs. $10 \mathrm{mg} / \mathrm{Kg}$ for $\mathbf{a}-\mathbf{d}$, $\mathbf{g}$; or when $* P<0.05$; $* * P<0.01$ between two groups for $\mathbf{f}$. $\mathbf{h}$ $\alpha$ Klotho and $\alpha$-SMA mRNA expression in kidney lysates at 20 weeks after the injection. Data are expressed as means \pm SD from each group and statistical significance was evaluated by unpaired Student- $t$-test and significance was accepted when $* P<0.05 ; * * P<0.01$ between two groups for $\mathbf{e}$ and $\mathbf{h}$. BUN blood urea nitrogen; $\mathrm{Cr}$ creatinine; $\mathrm{CP}$ cisplatin; HE Hematoxylin and Eosin stain; IP intraperitoneal injection; Pi plasma phosphate; TC Trichrome stain; PSR Picrosirius red stain

Table 1 Comparison of differences of the manifestations of acute kidney injury between male and female mice injected with cisplatin at 3 months of age

\begin{tabular}{llll}
\hline & Male & Female & $P$-value \\
\hline Animal number & 4 & 5 & \\
$\mathrm{BUN}(\mathrm{mg} / \mathrm{dl})$ & $91.5 \pm 5.4$ & $80.4 \pm 4.6$ & 0.0125 \\
$\mathrm{Cr}(\mathrm{mg} / \mathrm{dl})$ & $0.71 \pm 0.05$ & $0.64 \pm 0.04$ & 0.05 \\
$\mathrm{Cr}_{\mathrm{Cl}}(\mathrm{ml} / \mathrm{min} / 100 \mathrm{~g} \mathrm{BW})$ & $0.22 \pm 0.01$ & $0.26 \pm 0.02$ & $<0.05$
\end{tabular}

Data were presented as means \pm SD at 7 days after cisplatin injection $(10 \mathrm{mg} / \mathrm{Kg})$. The statistical significance was analyzed by unpaired Student $t$-test

protein concentration $(\mu \mathrm{g} / \mathrm{mg}$ protein) determined by Bradford protein assay.

\section{Real-time reverse transcription-polymerase chain reaction ( $R T-P C R)$}

Total RNA was extracted by RNAeasy kit (Qiagen, Germantown, MD) from mouse kidneys. Complimentary DNA (cDNA) was generated with oligo-dT primers using SuperScript III First Strand Synthesis System (Invitrogen, Carlsbad, CA) according to manufacturer's protocol. Primers used for qPCR are shown in Supplementary Table 1 with conditions described $[8,11,22,24]$. The reaction was performed in triplicate for each sample. Data are expressed at amplification number of $2^{-\Delta \Delta \mathrm{Ct}}$ by normalization of cyclophilin and comparison to controls.

\section{Statistical analyses}

Data are expressed as means $\pm \mathrm{SD}$. Analysis was performed with Sigma Stat software (Systat Software, Inc., San Jose, CA). As appropriate, statistical analysis was performed using unpaired Student- $t$-test, or one-way analysis of variance (ANOVA) followed by Student-Newman-Keuls post hoc test when applicable. A value of $P \leq 0.05$ was considered statistically significant.

\section{Results}

\section{Acute dose-dependent CP nephrotoxicity}

As the severity of kidney injury is an important independent contributor to AKI-to-CKD progression [29], we tested the effect of CP dosage on kidney damage and mortality. Mice given higher dose $(20 \mathrm{mg} / \mathrm{Kg}) \mathrm{CP}$ had higher mortality compared to lower dose $(10 \mathrm{mg} / \mathrm{Kg})$ (Fig. 1a). The higher dose $\mathrm{CP}$ also caused more significant elevation of plasma creatinine $\left(\mathrm{P}_{\mathrm{Cr}}\right)($ Fig. $1 \mathrm{~b})$ and plasma phosphate (Pi) (Fig. 1c) at early phase (2 weeks after $\mathrm{CP}$ injection) compared to the lower dose. All of the mice injected with high dose CP died $\sim 3$ weeks postinjection, which may be useful for studying AKI and mortality but renders the study of CKD progression impossible.

\section{Gender effect on AKI}

To explore the effect of gender on severity of AKI, we examined for differences of blood urea nitrogen (BUN) and $\mathrm{P}_{\mathrm{Cr}}$ between male and female mice at $7^{\text {th }}$ day after $\mathrm{CP}$ $(10 \mathrm{mg} / \mathrm{Kg})$ injection and found more severe kidney injury in male mice compared to female mice (Table 1), which is consistent with a previous study of CP nephrotoxicity in rats [30].

\section{Chronic kidney disease from CP}

By 20 weeks after low dose of CP injection $(10 \mathrm{mg} / \mathrm{Kg})$, mice developed moderate renal insufficiency as evident by elevation of plasma Cr (Fig. 1b), Pi (Fig. 1c), urinary albumin/creatinine ratio (ACR) (Fig. 1d), and alteration of renal histology including dilated or collapsed Bowman's space, glomerular sclerosis, renal tubular degeneration, vacuolation or necrosis, and interstitial infiltration and fibrosis (Fig. 1e, and Supplementary Fig. 1). In addition, CP-injected mice had lower renal $\alpha$ Klotho (Fig. 1f, g) at 1 week and sustained lower $\alpha$ Klotho and higher $\alpha$-SMA in the kidney (Fig. 1f, h) at 20 weeks, which are typical for CKD [8-11, 31]. 
Fig. 2 Aged mice are more vulnerable to acute cisplatin (CP) nephrotoxicity and at higher risk for CKD. WT mice at 3,6 , and 12 months old were injected with $\mathrm{CP}(10 \mathrm{mg} / \mathrm{Kg})$ or normal saline as vehicle (veh) and sacrificed at 20 weeks. a Creatinine clearance $\left(\mathrm{Cl}_{\mathrm{Cr}}\right)$. b Blood urea nitrogen (BUN).

c Plasma phosphate $(\mathrm{Pi})$. d Albumin-to-creatinine ratio (ACR). e Kidney histology assessed by HE, TC, and PSR stain (scale bar $=500 \mu \mathrm{m}$ ); and semi-quantitative assessment (right panel including chronic pathologic score based on HE stain and renal fibrosis score based on PSR stain). $\mathbf{f} \alpha$ Klotho and fibrotic markers in the kidney. Left panel:

representative immunoblot for $\alpha$ Klotho, $\alpha$-SMA, and CTGF in total kidney lysates. Right panel: summary of all immunoblots.

Data are expressed as means \pm SD from each group and statistical significance was evaluated by one-way ANOVA followed by

Student-Newman-Keuls post hoc test, and significance was accepted when $* P<0.05$; $* * P<$ 0.01 between two groups. HE Hematoxylin and Eosin stain;

TC Trichrome stain; PSR

Picrosirius red stain
A.

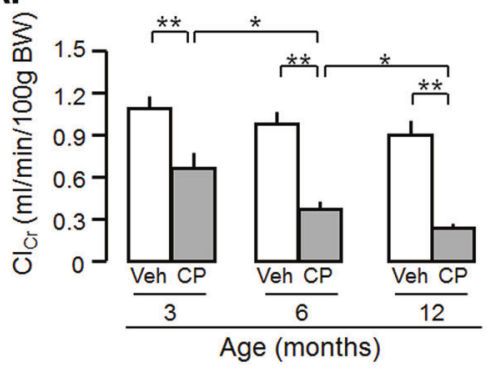

C.

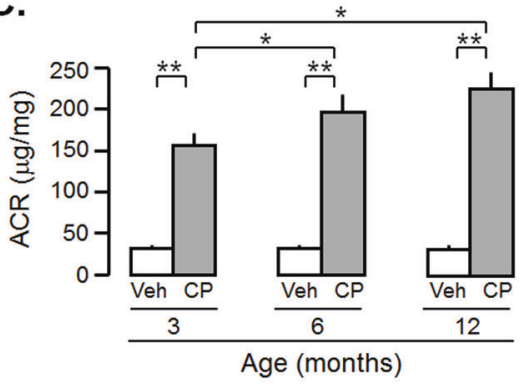

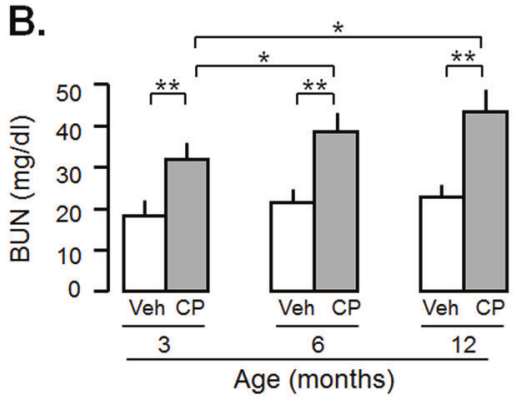

D.

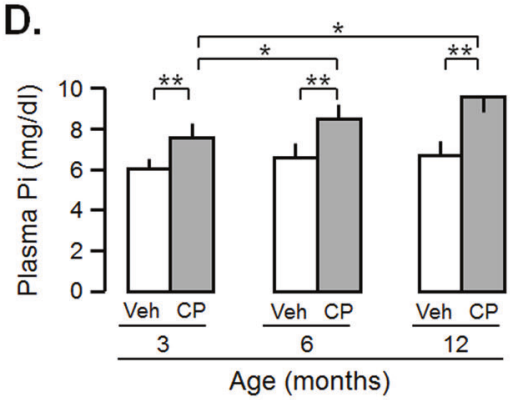

E.
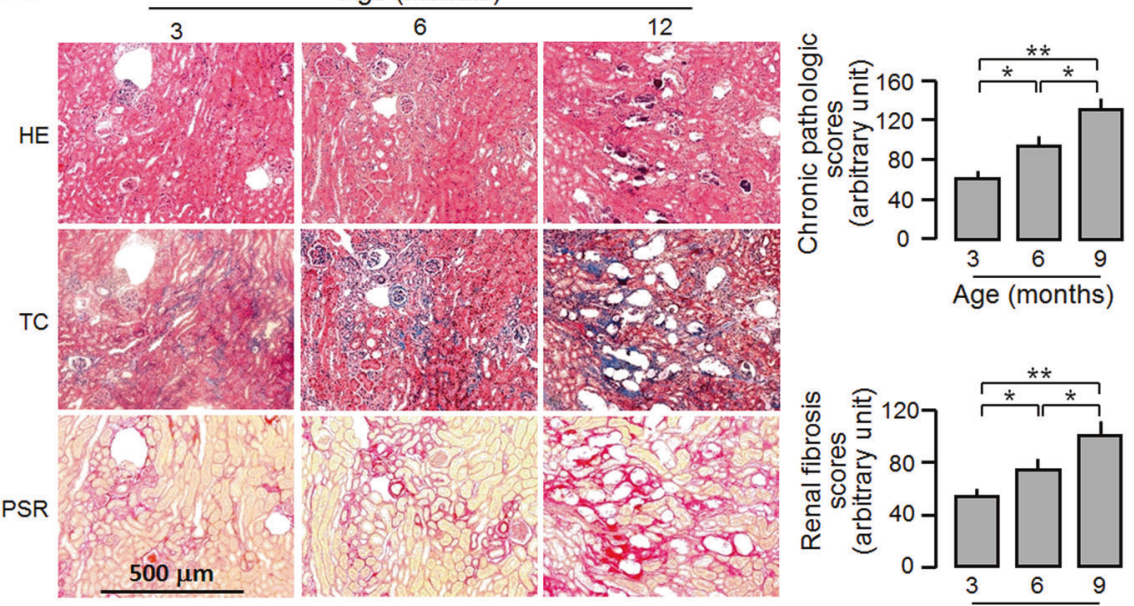

F.

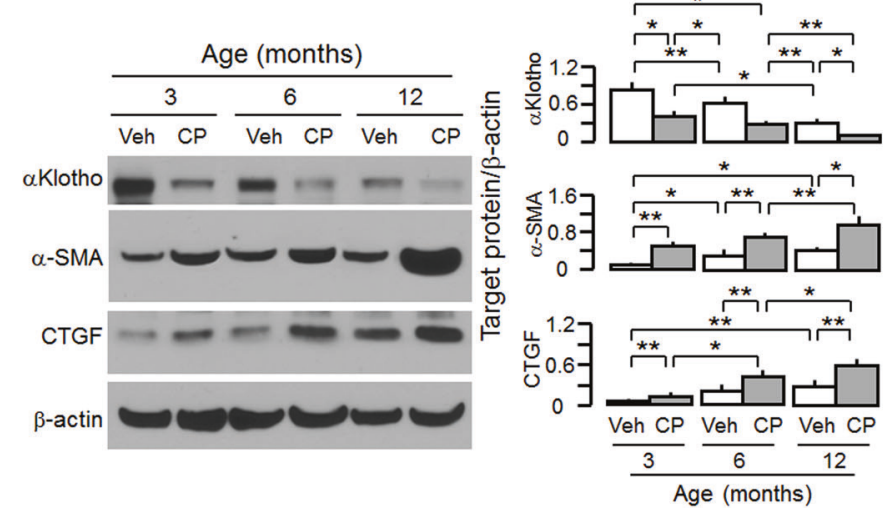

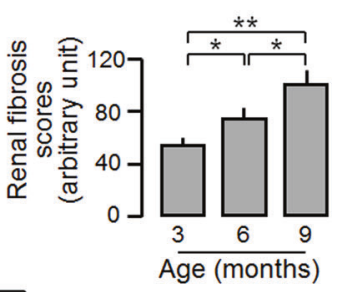


Fig. 3 High phosphate $(\mathrm{Pi})$ diet exacerbates renal fibrosis and renal $\alpha$ Klotho reduction in CKD mice. $W T$ mice at 3 months old were injected with $\mathrm{CP}(10 \mathrm{mg}$ / $\mathrm{Kg}$ ) or normal saline as vehicle (veh) followed by normal (NP) or high Pi (HP) diet (2.0\% Pi), respectively, for 18 weeks starting 2 weeks after CP injection. a Creatinine clearance $\left(\mathrm{Cl}_{\mathrm{Cr}}\right)$. b Plasma phosphate (Pi). c Kidney histology assessed by HE, TC, and PSR stain (scale bar $=500 \mu \mathrm{m}$ ); and semiquantitative assessment (bottom panel including chronic pathologic score based on HE stain and renal fibrosis score based on PSR stain). $\mathbf{d} \alpha$ Klotho and fibrotic markers in the kidney. Left panel: representative immunoblot for $\alpha$ Klotho, $\alpha$-SMA, and CTGF protein in total kidney lysates. Right panel: summary of all immunoblots. Data are expressed as means $\pm \mathrm{SD}$ from each group and statistical significance was evaluated by one-way ANOVA followed by Student-Newman-Keuls post hoc test and significance was accepted when $* P<0.05$; $* * P<$ 0.01 between two groups. HE Hematoxylin and Eosin stain; TC Trichrome stain; PSR Picrosirius red stain
A.

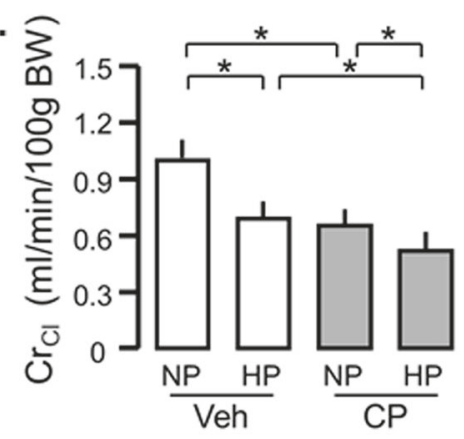

C.
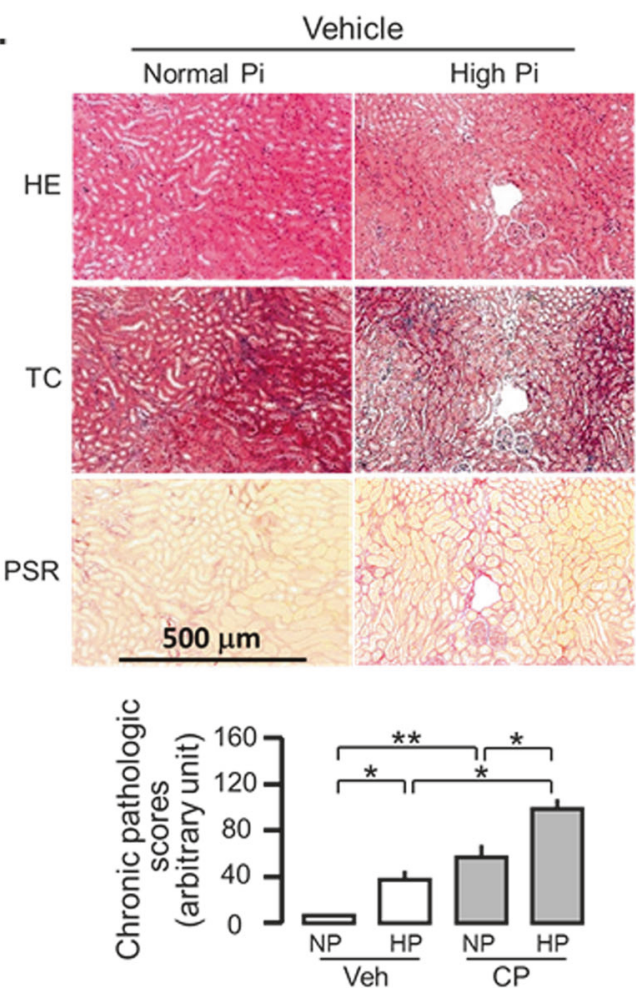

D. $\frac{\text { Vehicle }}{\mathrm{NP} \mathrm{HP}} \frac{\mathrm{CP}}{\mathrm{NP} \mathrm{HP}}$

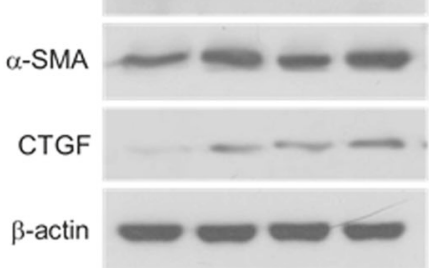

B.
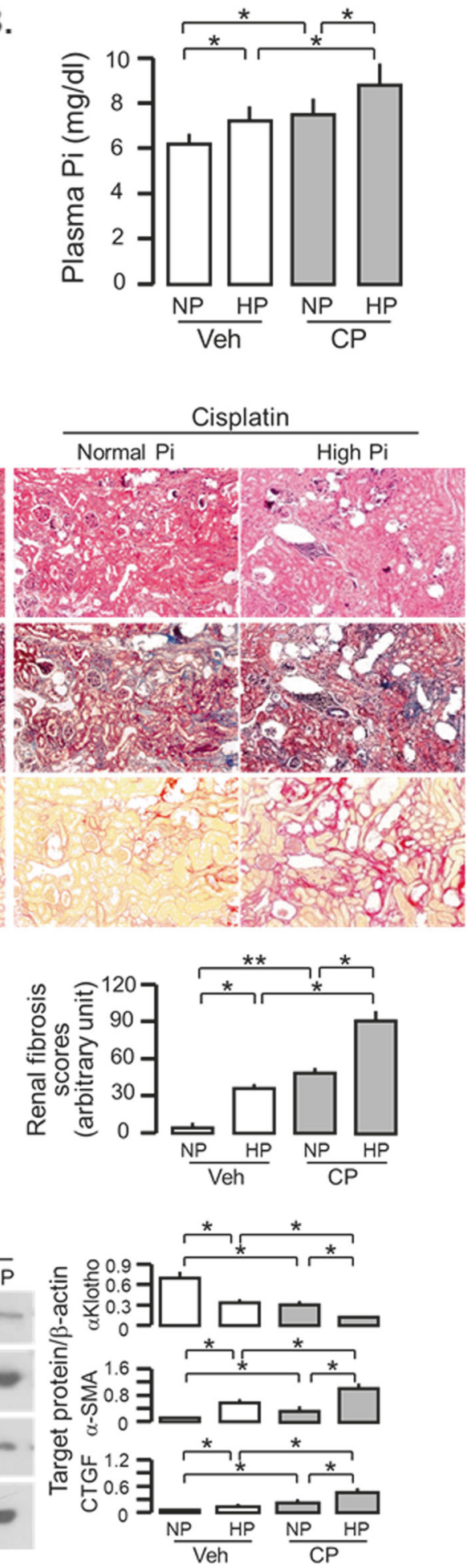

\section{Effect of age on AKI and AKI-to-CKD transition}

Older rats had more severe acute kidney damage after CP injection [32], which differs from human study [33]. To further define the age effect on the severity of $\mathrm{CP}$ nephrotoxicity in mice, we injected $\mathrm{CP}$ into three groups of mice at ages: 3,6 , and 12 months old. Clearly, after $\mathrm{CP}$ injection, 12-months-old mice had more severe decline in $\mathrm{Cl}_{\mathrm{Cr}}$ (Fig. 2a) and significantly higher BUN (Fig. 2b), plasma Pi (Fig. 2c), and ACR (Fig. 2d) than 3months-old mice. There was more kidney morphologic changes and renal fibrosis in 12-months-old mice 

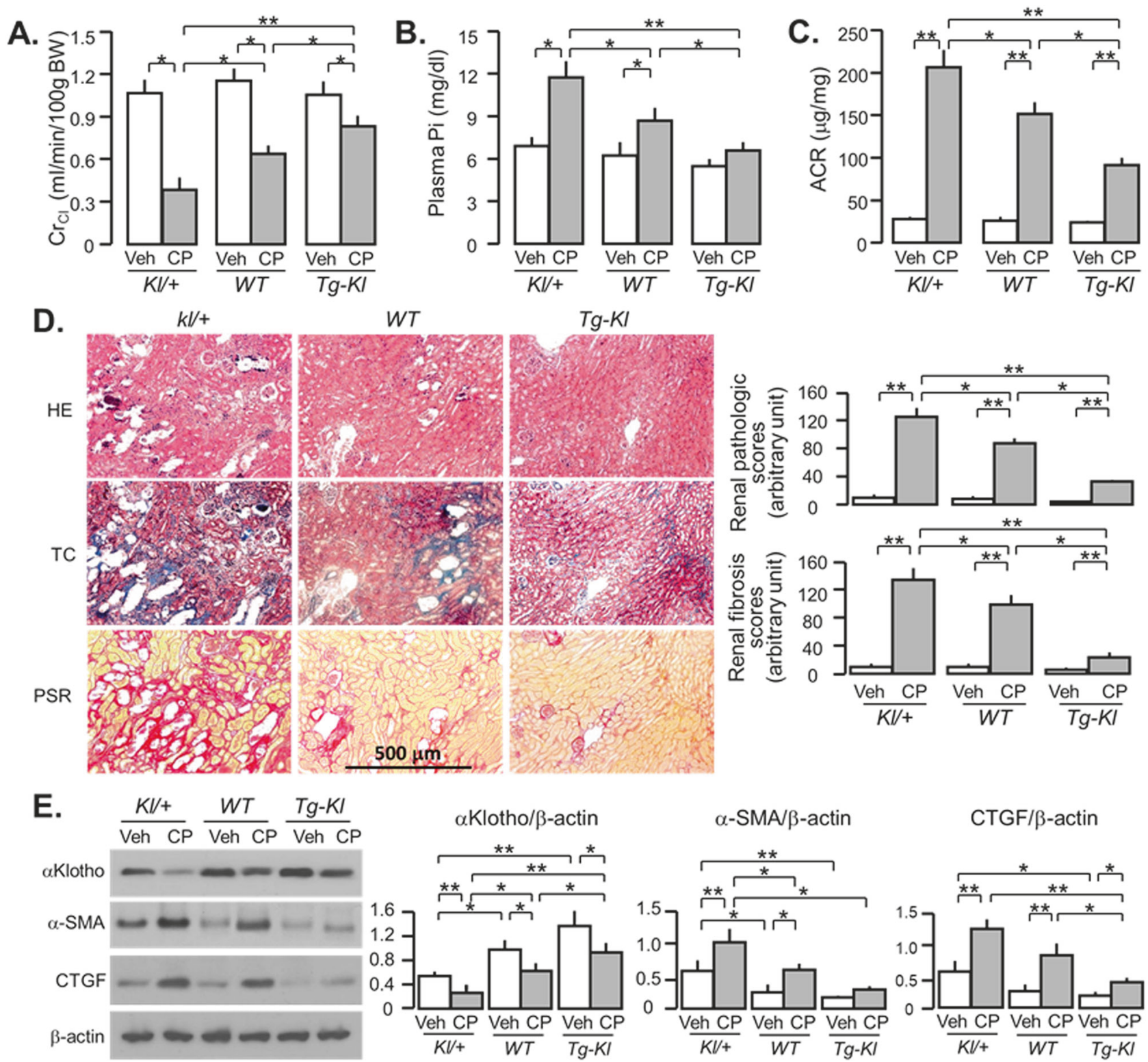

Fig. $4 \alpha$ Klotho-deficient mice progress more rapidly to CKD after cisplatin $(\mathrm{CP})$ injection. Mice with three different levels of $\alpha$ Klotho (low $k l /+$; normal $W T$; and high $T g-K l$ ) at 3 months old were intraperitoneally injected with normal saline as vehicle or CP $(10 \mathrm{mg} / \mathrm{Kg})$, and fed high phosphate $(\mathrm{Pi})$ rodent chow 2 weeks after the injection for 18 weeks. a Creatinine clearance $\left(\mathrm{Cl}_{\mathrm{Cr}}\right)$. b Plasma phosphate $(\mathrm{Pi})$. c Albumin-to-creatinine ratio (ACR). d Kidney histology assessed by $\mathrm{HE}, \mathrm{TC}$, and PSR stain (scale bar $=500 \mu \mathrm{m}$ ); and semi-quantitative assessment (right panel including chronic pathologic score based on HE stain and renal fibrosis score based on PSR stain). e $\alpha$ Klotho and

injected with $\mathrm{CP}$ compared to 3 months old (Fig. 2e). There was more reduction of $\alpha$ Klotho and increase in fibrotic markers in the kidneys in 12-months-old mice compared to those in 3-months-old mice (Fig. 2f). The $\mathrm{CP}$-induced changes in 6-months-old mice were intermediate between the 3 and 12-months-old-mice (Fig. 2), indicating older age is associated with more severe CKD fibrotic markers in the kidney. Left panel: representative immunoblotting for $\alpha$ Klotho, $\alpha$-SMA, and CTGF protein in total kidney lysates. Right panel: summary of immunoblots in arbitrary units from all immunoblots. Data are expressed as means \pm SD from each group and statistical significance was evaluated by one-way ANOVA followed by Student-Newman-Keuls post hoc test, and significance was accepted when $* P<0.05 ; * * P<0.01$ between two groups. HE Hematoxylin and Eosin stain; TC Trichrome stain; PSR Picrosirius red stain

with less $\alpha$ Klotho expression, and more renal fibrosis. To explore whether the age dependence is generalized in rodents, we also injected $10 \mathrm{mg} / \mathrm{Kg} \mathrm{CP}$ into 2 and 12 months-old SD rats respectively. Similarly, more severe kidney injury was found in older compared to younger rats (Supplementary Fig. 2) supporting that this is an universal finding. 
A.

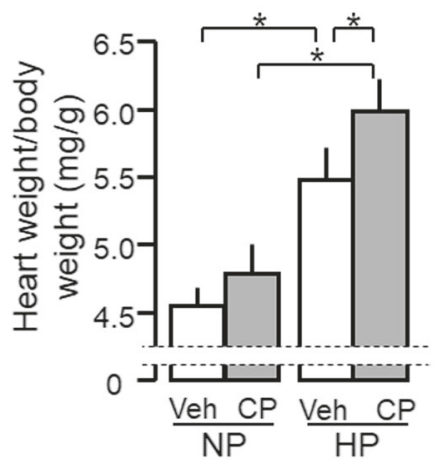

B.

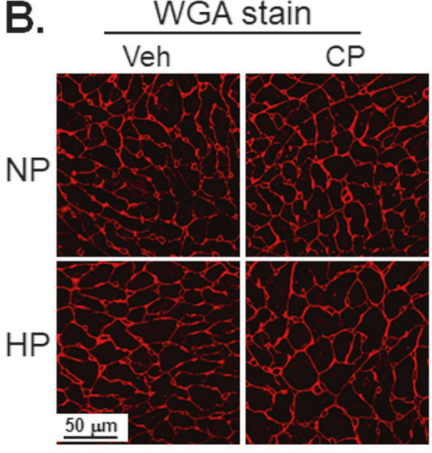

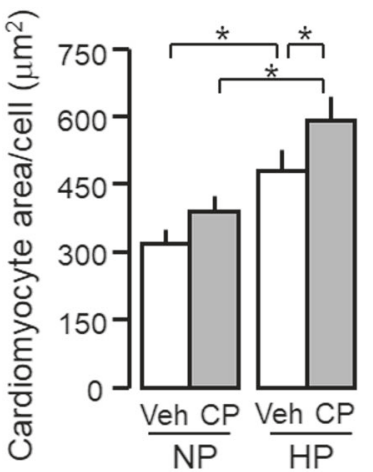

C. Trichrome stain

NP

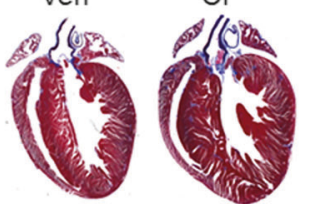

HP

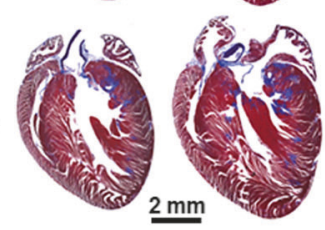

D.

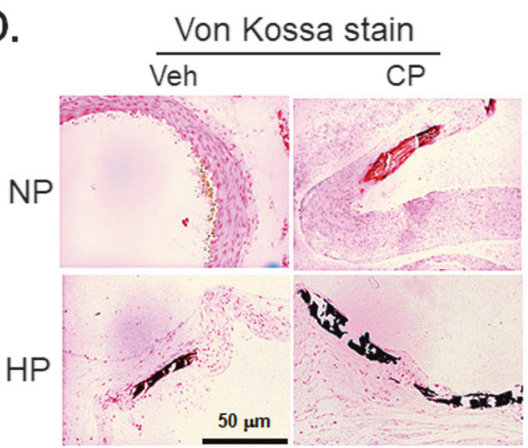

Fig. 5 High phosphate $(\mathrm{Pi})$ diet promotes cardiovascular disease in CKD mice. WT mice at 3 months old were injected with CP $(10 \mathrm{mg} /$ $\mathrm{Kg}$ ) or normal saline as vehicle (veh) followed by normal (NP) or high phosphate diet (HP, $2.0 \% \mathrm{Pi}$ ) for 18 weeks starting 2 weeks after CP injection. At 20 weeks after the injection, mice were sacrificed and the hearts and aorta were collected for morphology and molecular studies. a Heart weight/body weight. b Wheat germ agglutinin (WGA) stain: Left panel: representative microscopic images with WGA in heart section, scale bar $=50 \mu \mathrm{m}$. Right panel: sizes of cardiomyocytes were obtained from WGA-stained section with Image J program. c Cardiac fibrosis. Left panel: representative Trichrome staining in a heart

\section{High phosphate promotes AKI-to-CKD progression after CP-induced AKI}

Human observational studies showed a relationship between excessive phosphate and abnormal phosphate metabolism and cardiovascular disease (CVD) in the general population
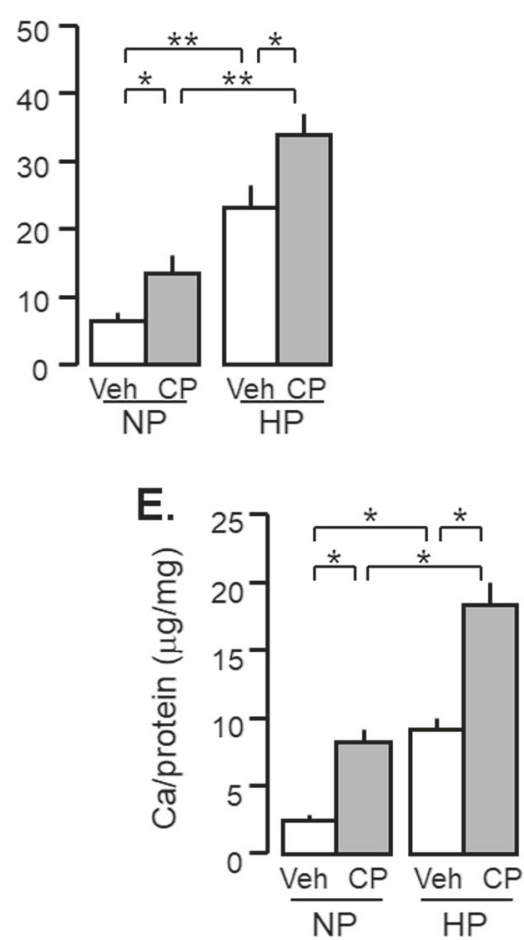

sections, scale bar $=2 \mathrm{~mm}$. Right panel: cardiac fibrosis score. d Von Kossa stain: there were $0 / 10$ positive stain in Veh-NP, 2/6 positive stain in CP-NP, $2 / 10$ positive stain in Veh-HP, and $5 / 8$ positive stain in CP-HP group. Representative micrographs of positive stain in the aortic roots. Scale bar $=50 \mu \mathrm{m}$. e Calcium content in the thoracic aorta with o-cresolphthalein complexone (OCPC) assay. Data are expressed as means \pm SD from each group and statistical significance was evaluated by one-way ANOVA followed by Student-Newman-Keuls post hoc test, and significance was accepted when $* P<0.05 ; * * P<0.01$ between two groups

and CKD population [34-40]. However, evidence for direct pathogenic effects of phosphate on cardiovascular events and kidney disease progression were strictly derived from rodent experimental data $[10,11,41-43]$. High dietary phosphate modestly, but significantly reduced $\mathrm{Cl}_{\mathrm{Cr}}$ and increased plasma Pi in vehicle-injected mice, but remarkably 
Table 2 Association of cisplatin doses with the changes in mineral metabolism and renal function in $W T$ mice at 20 weeks after cisplatin or vehicle injection at 3 months of age

\begin{tabular}{|c|c|c|c|c|}
\hline & \multicolumn{2}{|c|}{ Cisplatin- $0 \mathrm{mg} / \mathrm{kg}$} & \multicolumn{2}{|c|}{ Cisplatin-10 mg/kg } \\
\hline & NP & HP & $\mathrm{NP}$ & $\mathrm{HP}$ \\
\hline Animal number & 10 & 10 & 9 & 8 \\
\hline BUN (mg/dl) & $19.3 \pm 0.8$ & $28.6 \pm 1.3^{*}$ & $31.7 \pm 1.5 * *$ & $43.9 \pm 2.2 * *, \#, \$$ \\
\hline $\mathrm{Cr}(\mathrm{mg} / \mathrm{dl})$ & $0.08 \pm 0.01$ & $0.19 \pm 0.07 *$ & $0.31 \pm 0.18^{* *, \#}$ & $0.52 \pm 0.23 * *, \# \#, \$$ \\
\hline $\mathrm{Cr}_{\mathrm{Cl}}(\mathrm{ml} / \mathrm{min} / 100 \mathrm{~g} \mathrm{BW})$ & $1.11 \pm 0.06$ & $0.90 \pm 0.07$ & $0.73 \pm 0.05$ & $0.58 \pm 0.03 * *, \# \#, \$$ \\
\hline Plasma Pi (mg/dl) & $6.38 \pm 0.21$ & $7.03 \pm 0.85$ & $7.91 \pm 0.28$ & $8.47 \pm 0.69 * *, \# \#, \$$ \\
\hline Plasma Ca (mg/dl) & $9.25 \pm 0.05$ & $9.09 \pm 0.08$ & $9.15 \pm 0.07$ & $9.01 \pm 0.05^{*}$ \\
\hline Plasma PTH (pg/ml) & $103 \pm 31$ & $219 \pm 19 *$ & $305 \pm 47 * *, \#$ & $439 \pm 54 * *, \# \#, \$ \$$ \\
\hline Plasma $1,25-(\mathrm{OH})_{2} \mathrm{D}_{3}(\mathrm{pg} / \mathrm{ml})$ & $109.2 \pm 4.8$ & $78.7 \pm 4.5^{*}$ & $67.9 \pm 5.8^{*}$ & $49.2 \pm 3.6^{* *, \#}$ \\
\hline Plasma FGF23 (pg/ml) & $163 \pm 39$ & $647 \pm 358 * *$ & $1832 \pm 237 * * \# \#$ & $2390 \pm 494 * *, \# \#, \$$ \\
\hline
\end{tabular}

$N P$ normal Pi diet, $H P$ high Pi diet

Data are expressed as means \pm SD from each group and statistical significance was evaluated by one-way ANOVA followed by Student-Newman-Keuls post hoc test, and significance was accepted when $* P<0.05$; ${ }^{* *} P<0.01$ vs. NP at $0 \mathrm{mg} / \mathrm{Kg} ;{ }^{\#} P<0.05 ;{ }^{\# \#} P<0.01$ vs. HP at $0 \mathrm{mg} / \mathrm{Kg} ;{ }^{\$} P<0.05 ;{ }^{\$ \$} P<0.01$ vs. NP at $10 \mathrm{mg} / \mathrm{Kg}$ exacerbated these changes in $\mathrm{CP}$-injected mice compared to CP-injected mice fed a normal phosphate diet (Fig. 3a, b). Furthermore, the levels of BUN, and plasma $\mathrm{Cr}$ and $\mathrm{Pi}$ was much higher in CP-injected and high Pi-fed mice compared to other three groups starting at 10 weeks after CP injection (Supplementary Fig. 3), indicating that high dietary phosphate accelerated AKI-to-CKD progression. Kidney histology study showed more changes in kidney structure and more visible renal fibrosis in high phosphate fed mice in both vehicle and CP-injected mice (Fig. 3c, and Supplementary Fig. 4). The highest level of fibrotic markers were in the kidneys of CP-injected mice fed a high phosphate diet, and moderate elevations of those markers in either high phosphate fed mice alone or CP-injected mice alone, compared to vehicle-injected mice fed a normal phosphate diet (Fig. 3d). High phosphate diet did not only decrease renal $\alpha$ Klotho protein expression in vehicle-injected mice, but also exacerbated the decline in renal $\alpha$ Klotho protein levels in CP-injected mice (Fig. 3d).

\section{Effect of aKlotho levels on the severity of AKI and CKD after CP injection}

We have shown that $\alpha$ Klotho levels prior to renal insults influence renal outcome and the speed of progression to CKD after IRI-induced AKI [8]. As expected, heterozygous $\alpha$ Klotho-deficient $(K l /+)$ mice had lower $\mathrm{Cl}_{\mathrm{Cr}}$ (Fig. 4a), higher plasma Pi levels (Fig. 4b), and ACR (Fig. 4c) compared to WT mice. Transgenic mice with Klotho overexpression $(T g-K l)$ had the opposite changes, supporting our previous findings in IRI model [8]. Kidney histology showed more alterations of kidney structure and severe fibrosis in $\mathrm{Kl} /+$ and milder changes in $T g-K l$ mice compared to WT mice at 20 weeks after CP injection (Fig. 4d, and Supplementary Fig. 4). The higher levels of $\alpha$-SMA and CTGF protein expression in $K l /+$ mice and lower levels in $T g$ - $K l$ mice compared to $W T$ mice (Fig. 4e), are in line with the changes in TC and PSR stain. As anticipated, $\alpha$ Klotho levels were higher in $T g-K l$ mice and lower in $K l /+$ mice compared to WT mice in both vehicle and CP-treated conditions (Fig. 4e). Because $T g-K l$ mice have milder kidney damage at acute stage [24], the better renal outcome at chronic stage (Fig. 4) could not be solely interpreted as retardation of CKD progression. Moreover, after CP injection, $T g-K l$ mice had lower renal Klotho protein than prior to injection, but still maintained higher Klotho compared to $W T$ mice received $\mathrm{CP}$, thus less kidney damage and mild renal fibrosis in $\mathrm{Tg}-\mathrm{Kl}$ mice receiving $\mathrm{CP}$ is likely attributable to higher renal and circulating Klotho.

\section{Cardiovascular disease in CP-induced CKD}

As CVD is the major cause of mortality in CKD; a relevant experimental AKI-to-CKD transition model should exhibit CVD. CP-injected mice had heavier hearts (Fig. 5a) and larger cardiomyocytes (Fig. 5b) than vehicle-injected mice after high dietary phosphate intake. We also found that 18week high Pi diet alone was sufficient to initiate cardiac hypertrophy in $W T$ mice with normal kidney function (Fig. 5a, b). Furthermore, high phosphate diet-induced cardiac fibrosis were more appreciable in CP-injected mice than vehicle-injected mice (Fig. 5c).

In addition to cardiac remodeling, severe vascular calcification was found in CP-injected mice after high dietary phosphate intake. Much less vascular calcification was seen in CP-injected mice without high phosphate diet (Fig. 5d). Quantitative determination of calcium content in aorta showed the highest levels of calcium in CP-treated mice 
A.

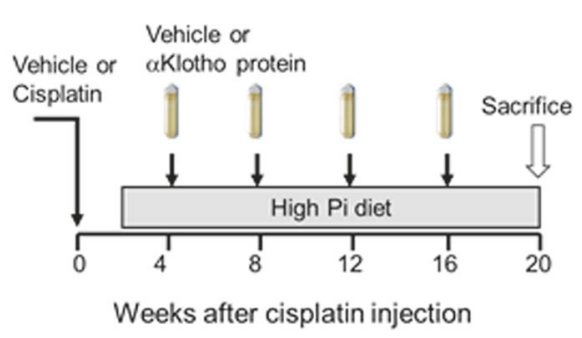

B.

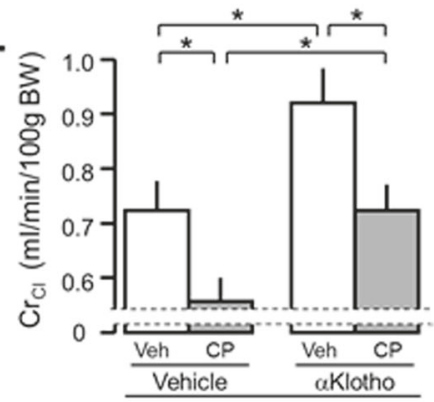

D.

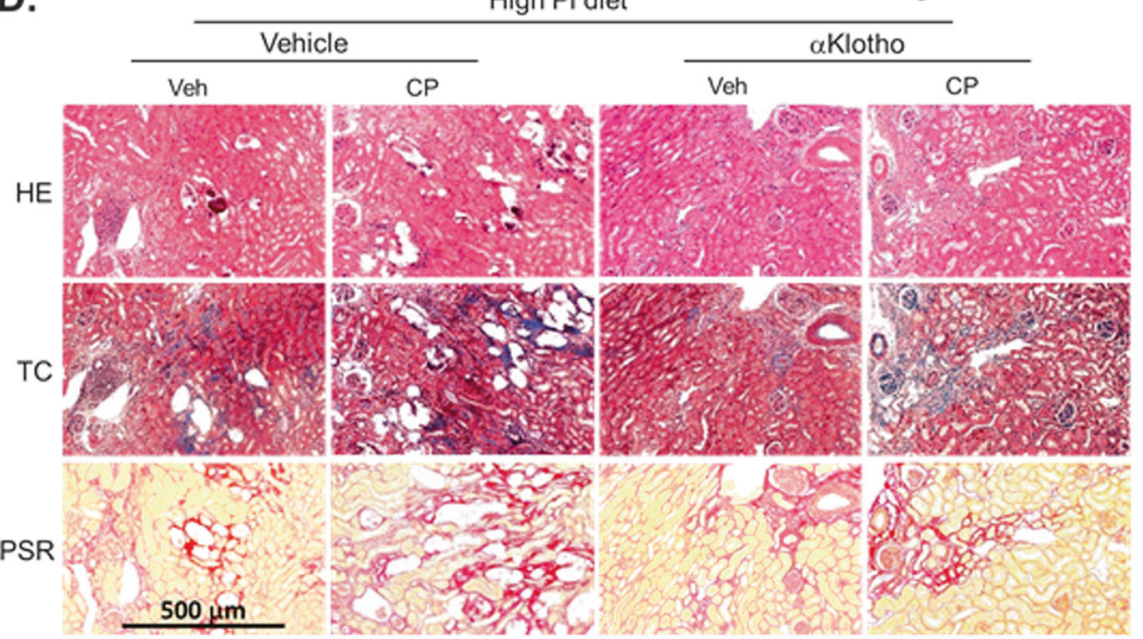

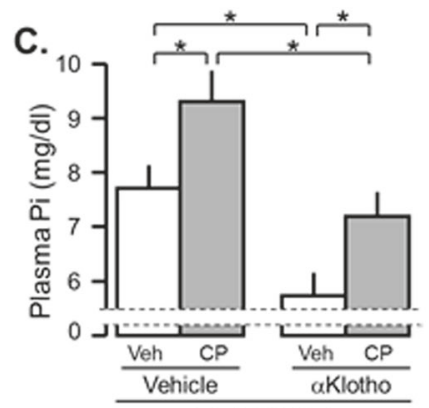

High Pi diet

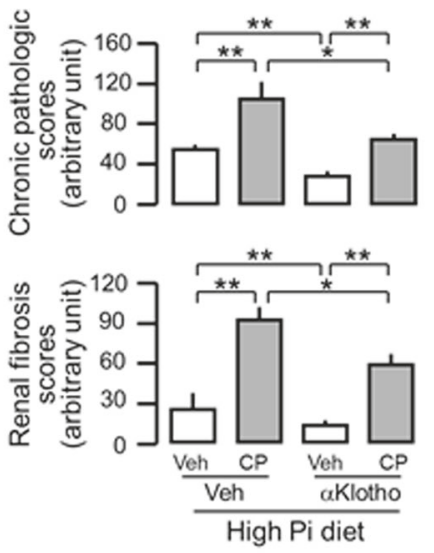

E.
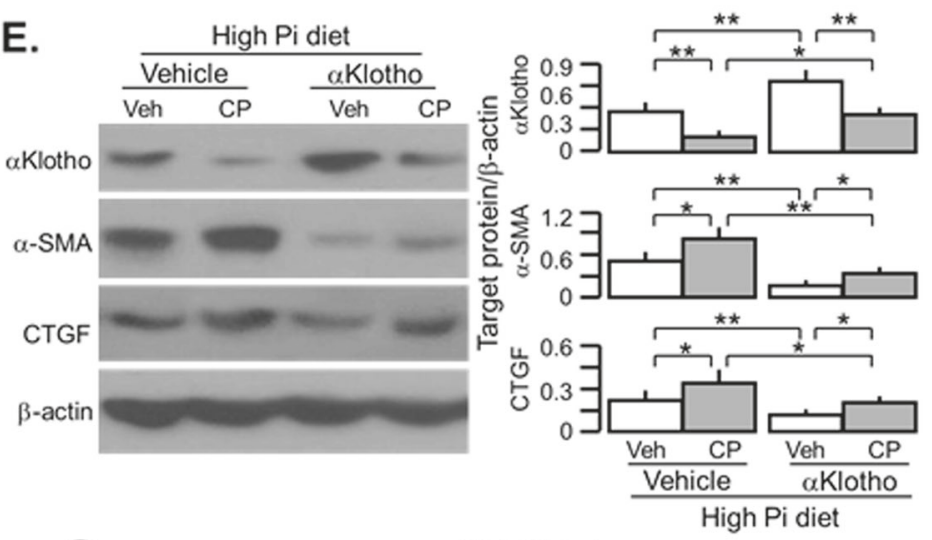

G.

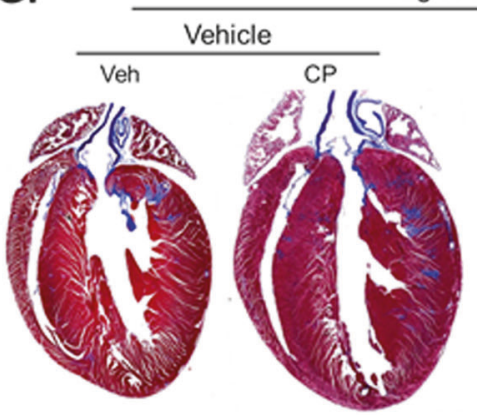

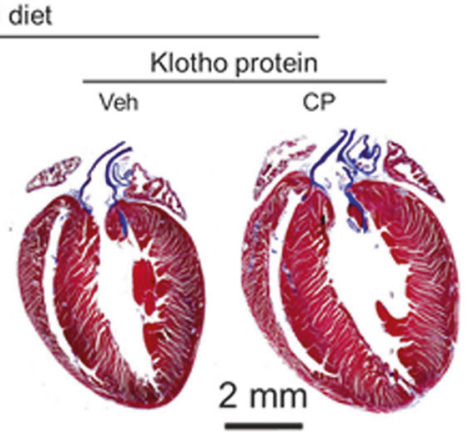

F.
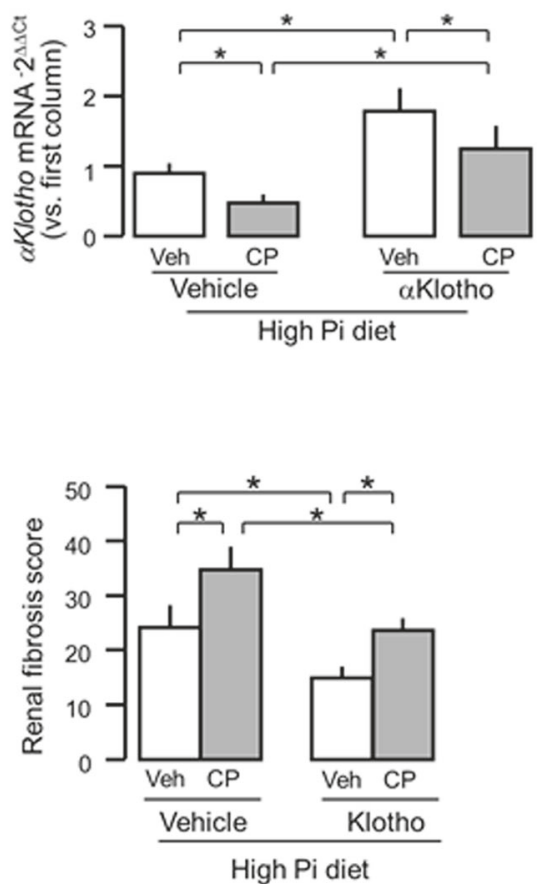

with high phosphate diet, moderate levels in either CPinjected mice with normal phosphate diet or vehicleinjected mice with high phosphate diet (Fig. 5e).
Therefore, CP-injected mice developed AKI in acute stage and progressed to $\mathrm{CKD}$ with the full range of disturbed mineral homeostasis (Table 2), renal fibrosis, cardiac 
Fig. $6 \alpha$ Klotho administration post-cisplatin $(\mathrm{CP})$ injection retards AKI-to-CKD progression. a WT mice at 3 months old were intraperitoneally injected with $\mathrm{CP}(10 \mathrm{mg} / \mathrm{Kg})$ or normal saline as vehicle (veh) followed by feeding with high Pi diet in 2 weeks after the injection for 18 weeks. At 4 weeks after the injection, $\alpha$ Klotho protein or control buffer (normal saline) was given through osmotic minipumps for 16 weeks. At 20 weeks after the injection, mice were sacrificed and the kidneys, and urine and plasma samples were collected for further studies. b Creatinine clearance $\left(\mathrm{Cl}_{\mathrm{Cr}}\right)$. c Plasma phosphate (Pi). d Kidney histology assessed by HE, TC, and PSR stain (scale bar $=500 \mu \mathrm{m}$ ); and semi-quantitative assessment (right panel including chronic pathologic score based on HE stain and renal fibrosis score based on PSR stain). e $\alpha$ Klotho protein and fibrotic markers in the kidney. Left panel: representative immunoblot for $\alpha$ Klotho, $\alpha$ SMA, and CTGF protein in total kidney lysates. Right panel: summary of all immunoblots. $\mathbf{f} \alpha$ Klotho mRNA expression in the kidney lysate. g Cardiac fibrosis at 20 weeks after the injection. Left panel: representative Trichrome staining in heart sections, scale bar $=2 \mathrm{~mm}$. Right panel: cardiac fibrosis score. Data are expressed as means \pm SD from each group and statistical significance was evaluated by one-way ANOVA followed by Student-Newman-Keuls post hoc test, and significance was accepted when $* P<0.05 ; * * P<0.01$ between two groups. HE Hematoxylin and Eosin stain; TC Trichrome stain; PSR Picrosirius red stain

remodeling, and vascular calcification after chronic high dietary phosphate loading (Fig. 5).

\section{Effect of aKlotho administration on AKI-to-CKD progression}

To examine the $\alpha$ Klotho effect on AKI-to-CKD transition after acute CP nephrotoxicity, we administered $\alpha$ Klotho intraperitoneally to mice after exposure to $\mathrm{CP}$ and high phosphate diet (Fig. 6a). We found better renal function (Fig. 6b), better phosphate homeostasis (Fig. 6c), and less renal fibrosis (Fig. 6d, e, and Supplementary Fig. 6) compared to CP-injected mice without $\alpha$ Klotho administration. In addition, we further confirmed the efficacy of recombinant $\alpha$ Klotho protein in retardation of AKI-to-CKD progression [8]. $\alpha$ Klotho-treated mice had lesser kidney injury and fibrosis, and higher native $\alpha$ Klotho protein in the kidney compared to vehicle-treated mice (Fig. 6e). Higher levels of renal $\alpha$ Klotho might result from better preservation of renal function and lower plasma Pi (Fig. 6f). Furthermore, $\alpha$ Klotho treatment significantly alleviated uremic cardiomyopathy (Fig. 6g). Obviously, this study design cannot discern whether better cardiac histology results from $\alpha$ Klotho's direct cardioprotective effect, secondary effects due to renoprotection and better renal function, or both.

\section{Gender effect on CKD progression}

We compared the difference in severity of CKD and cardiac hypertrophy between male and female mice given CP followed by normal or high $\mathrm{Pi}$ diet. Male mice had faster decline in renal function and rise in plasma Pi (Fig. 7a, b, and Table 3) in WT mice after CP-induced AKI, and were more sensitive to high Pi challenge with more severe loss of renal function and higher plasma Pi (Table 4 and Fig. 7c, d), more disturbed mineral metabolism and more cardiac hypertrophy than female mice (Table 4). These results are similar to clinical observations and some animal studies [44-48]. Similar to $W T$ mice, male $K l /+$ mice had worse renal function and higher plasma $\mathrm{Pi}$ than female mice, indicating that gender influences AKI progression to CKD (Fig. 7e, f). Furthermore, on the comparison of $\mathrm{Cl}_{\mathrm{Cr}}$ and plasma Pi between WT CKD mice (Fig. 7c, d, and Table 3) and $\alpha$ Klotho-treated WT CKD mice (Fig. 7g, h, and Table 5), exogenous $\alpha$ Klotho administration was more effective in improvement of kidney function and Pi metabolism in male CKD mice, because male mice had $33.0 \%$ elevation of $\mathrm{Cl}_{\mathrm{Cr}}$ from vehicle-treated CKD mice and $13.0 \%$ reduction of plasma $\mathrm{Pi}$ from vehicle-treated CKD mice (Tables 3, 5), while female mice only had $23 \%$ elevation of $\mathrm{Cl}_{\mathrm{Cr}}$ and $8.9 \%$ reduction of plasma Pi. Similarly, cardiac hypertrophy was attenuated by $26.4 \%$ in male CKD mice vs. $11.1 \%$ in female CKD mice when $\alpha$ Klotho was given. Therefore, male CKD mice benefit more from $\alpha$ Klotho protein administration compared to females, although male CKD mice still had worse renal function, Pi metabolism, and cardiomyopathy than female CKD mice.

\section{Discussion}

Most of the present knowledge on renal physiology and pathophysiology comes from the experimental study in laboratory animals. Discovery of novel therapeutic or diagnostic approaches primarily begins in animal models. Therefore, having a technically easy, reproducible, and stable experimental models of CKD is an essential step. We present a rodent model of a single bolus intraperitoneal injection of CP followed by high dietary phosphate intake that produces CKD in both mice and rats. The rodents develop AKI, as previously noted [24, 49-56], but importantly, one does not lose animals from AKI, and acute CP nephrotoxicity progresses to CKD with CVD and disturbed mineral metabolism relevant to human CKD. Therefore, this rodent model is suitable for the study of AKI, or AKI-toCKD progression or chronic complication, such as cardiovascular disease in CKD.

\section{Phenotypes of CP-model of AKI, AKI-to-CKD transition, and CKD-associated CVD}

Up to thirty-two percent of the patients after CP treatment develop AKI constituting the major limiting factor to human use of $\mathrm{CP}[13,14,57]$. Animal studies have shown that $\mathrm{CP}$-induced $\mathrm{AKI}$ can progress to $\mathrm{CKD}$ in certain scenarios 

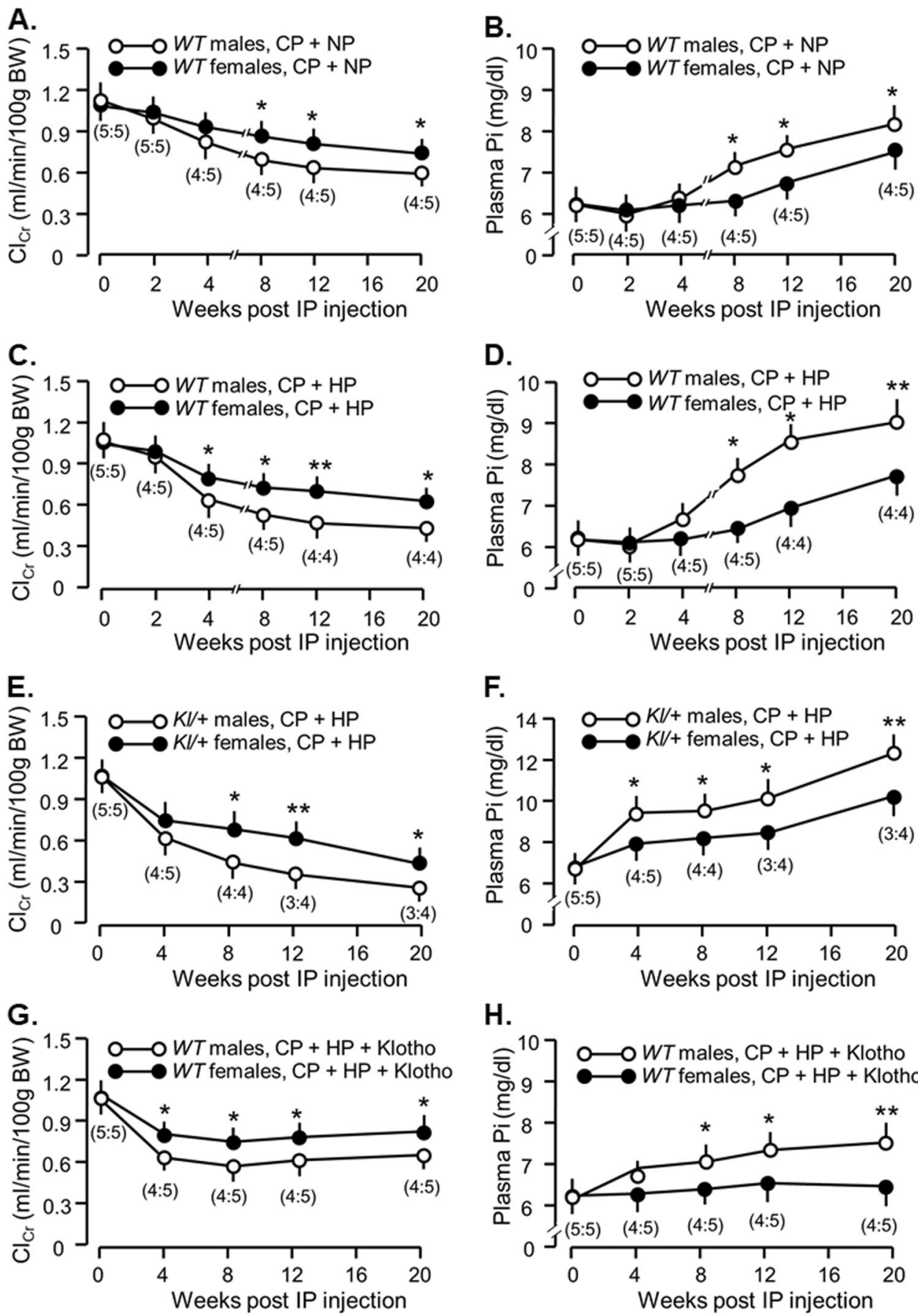

H.

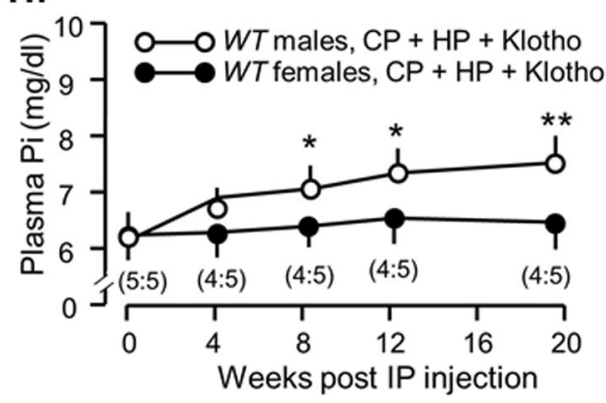

Fig. 7 Sexual dimorphism in CP-induced CKD progression and in the response to $\alpha$ Klotho treatment. WT mice at 3 months old were injected with CP $(10 \mathrm{mg} / \mathrm{Kg})$ or normal saline as vehicle (veh) followed by normal (NP) or high phosphate diet (HP, 2.0\% Pi) for 18 weeks starting 2 weeks after $\mathrm{CP}$ injection. At 20 weeks after the injection, mice were sacrificed. a Creatinine clearance $\left(\mathrm{Cl}_{\mathrm{Cr}}\right)$ and $\mathbf{b}$ plasma phosphate $(\mathrm{Pi})$ in male and female mice fed with normal $\mathrm{Pi}$ diet. $\mathbf{c}$ Creatinine clearance $\left(\mathrm{Cl}_{\mathrm{Cr}}\right)$ and $\mathbf{d}$ plasma phosphate $(\mathrm{Pi})$ in male and female mice fed with high Pi diet. Mice with low levels of $\alpha$ Klotho $(\mathrm{kl} /$ $+)$ at 3 months old were intraperitoneally injected with $\mathrm{CP}(10 \mathrm{mg} /$ $\mathrm{Kg}$ ), and fed high phosphate (Pi) rodent chow 2 weeks after the injection for 18 weeks. e Creatinine clearance $\left(\mathrm{Cl}_{\mathrm{Cr}}\right)$ and $\mathbf{f}$ plasma

phosphate $(\mathrm{Pi})$ in male and female $K l /+$ mice. $W T$ mice at 3 months old were intraperitoneally injected with $\mathrm{CP}(10 \mathrm{mg} / \mathrm{Kg})$ followed by feeding with high Pi diet in 2 weeks after the injection for 18 weeks. At 4 weeks after the injection, $\alpha$ Klotho protein was given through osmotic minipumps for 16 weeks. $\mathbf{g}$ Creatinine clearance $\left(\mathrm{Cl}_{\mathrm{Cr}}\right)$ and $\mathbf{h}$ plasma phosphate $(\mathrm{Pi})$ in male and female $W T$ mice. Data are expressed as means $\pm \mathrm{SD}$ from each group and statistical significance was evaluated by one-way ANOVA followed by Student-Newman-Keuls post hoc test, and significance was accepted when $* P<0.05$; $* * P<0.01$ between two groups at same time point. The number in brackets is male:female number in each group at different time point 
Table 3 Comparison of differences in manifestations of CKD and cardiac hypertrophy between male and female mice fed with a normal Pi diet

\begin{tabular}{|c|c|c|c|}
\hline & Male & Female & $P$-value \\
\hline Animal number & 4 & 5 & \\
\hline BUN (mg/dl) & $36.3 \pm 1.3$ & $31.7 \pm 1.9$ & $<0.01$ \\
\hline $\mathrm{Cr}(\mathrm{mg} / \mathrm{dl})$ & $0.34 \pm 0.09$ & $0.31 \pm 0.07$ & $<0.05$ \\
\hline $\mathrm{Cr}_{\mathrm{Cl}}(\mathrm{ml} / \mathrm{min} / 100 \mathrm{~g} \mathrm{BW})$ & $0.69 \pm 0.04$ & $0.77 \pm 0.06$ & $<0.05$ \\
\hline Plasma Pi (mg/dl) & $8.21 \pm 0.32$ & $7.62 \pm 0.24$ & $<0.05$ \\
\hline Plasma Ca (mg/dl) & $9.21 \pm 0.10$ & $9.11 \pm 0.07$ & $>0.05$ \\
\hline Plasma PTH $(\mathrm{pg} / \mathrm{ml})$ & $321 \pm 52$ & $291 \pm 42$ & $>0.05$ \\
\hline Plasma $1,25-(\mathrm{OH})_{2} \mathrm{D}_{3}(\mathrm{pg} / \mathrm{ml})$ & $70.4 \pm 6.2$ & $65.5 \pm 5.3$ & $>0.05$ \\
\hline Plasma FGF23 (pg/ml) & $2016 \pm 330$ & $1757 \pm 139$ & $>0.05$ \\
\hline Heart weight/body weight (mg/g) & $5.69 \pm 0.32$ & $5.28 \pm 0.31$ & 0.08 \\
\hline
\end{tabular}

Data presented in Table 3 are derived from mice injected cisplatin and treated with normal Pi diet presented in Table 2 and were shown as means \pm SD at 20 weeks. The statistical significance between male and female mice was analyzed by unpaired Student $t$-test

Table 4 Comparison of differences in manifestations of CKD and cardiac hypertrophy between male and female mice fed with a high Pi diet

\begin{tabular}{|c|c|c|c|}
\hline & Male & Female & $P$-value \\
\hline Animal number & 4 & 4 & \\
\hline BUN (mg/dl) & $48.4 \pm 3.4$ & $39.5 \pm 2.4$ & $<0.05$ \\
\hline $\mathrm{Cr}(\mathrm{mg} / \mathrm{dl})$ & $0.61 \pm 0.04$ & $0.43 \pm 0.03$ & $<0.01$ \\
\hline $\mathrm{Cr}_{\mathrm{Cl}}(\mathrm{ml} / \mathrm{min} / 100 \mathrm{~g} \mathrm{BW})$ & $0.51 \pm 0.04$ & $0.64 \pm 0.05$ & $<0.05$ \\
\hline Plasma Pi (mg/dl) & $9.04 \pm 0.71$ & $7.78 \pm 0.65$ & 0.058 \\
\hline Plasma Ca (mg/dl) & $8.97 \pm 0.75$ & $9.06 \pm 0.79$ & $>0.05$ \\
\hline Plasma PTH (pg/ml) & $516 \pm 49$ & $390 \pm 23$ & $<0.01$ \\
\hline Plasma $1,25-(\mathrm{OH})_{2} \mathrm{D}_{3}(\mathrm{pg} / \mathrm{ml})$ & $43.1 \pm 3.8$ & $56.4 \pm 4.9$ & $<0.05$ \\
\hline Plasma FGF23 (pg/ml) & $2700 \pm 325$ & $2081 \pm 196$ & $<0.05$ \\
\hline Heart weight/body weight (mg/g) & $6.61 \pm 0.42$ & $5.68 \pm 0.29$ & $<0.05$ \\
\hline
\end{tabular}

Data presented in Table 4 are derived from mice injected cisplatin and treated with high Pi diet presented in Table 2 and were shown as means \pm SD at 20 weeks. The statistical significance was analyzed by unpaired Student $t$-test

[16-20, 58, 59]. Basically, there are two strategies to induce CKD with CP (referred to [21] for detailed information). One is multiple injections. Decades ago, Marcussen reported that repeated low dose CP injection $(2 \mathrm{mg} / \mathrm{Kg} / \mathrm{week}$ for 10 weeks followed by 3 times/week for two weeks) induced chronic renal failure with atubular glomeruli, massive tubular dilation, and interstitial fibrosis in rats [60]. Sharp and colleagues showed that repeatedly weekly injection of moderate dose of $\mathrm{CP}$ (7-9 $\mathrm{mg} / \mathrm{Kg}$ body weight) consecutively for 4 weeks induced CKD [20]. Interestingly, repeated low doses of $\mathrm{CP}(1 \mathrm{mg} / \mathrm{Kg}$, twice weekly) for 10 weeks still effectively induced an increase in serum $\mathrm{Cr}$, interstitial fibrosis, tubular dilation, and atrophy in rats [18]. Torres and colleagues reported two injections of high dose CP (15 mg/Kg body weight) 2 weeks apart induced CKD around 9 weeks, and CKD progression by 25 weeks [19]. Okada showed that $5 \mathrm{mg} / \mathrm{Kg} \mathrm{CP}$ injection followed by repeating injection twice in 21-day interval dramatically decrease $\mathrm{Cl}_{\mathrm{Cr}}$ by $50 \%$ in rats [61]. When $\mathrm{CP}$ was repeatedly given weekly at $10 \mathrm{mg} / \mathrm{Kg}$, all mice died within 4 weeks [17]. So, if one elects repeated injection, the dose should be low enough or interval of injection should be longer to prevent animal death. The advantage of repeating low dose is that there is low cell injury or death, but high level of renal fibrosis [20, 21]. Second method is high dose of CP injection $(\geq 20 \mathrm{mg} / \mathrm{Kg}$ ), which induces serious kidney injury and inevitably ends with high mortality that prevents chronic studies (Fig. 1a) [20]. The CP-induced CKD is characterized by tubular atrophy and dilation, massive interstitial fibrosis and collagen deposition in the kidney, as well as peritubular capillary rarefaction [19]. But most, if not all, of these studies primarily focused on the changes in the kidney and none of them examined extra-renal complications in mineral metabolism and cardiovascular pathology [19, 20]. In addition, none of those experiments tested the role of high $\mathrm{Pi}$ in acceleration of CKD progression from acute CP nephrotoxicity. The current study clearly showed that mice do not only develop CKD with renal fibrosis, uremia, and CKD-MBD, but also uremic cardiomyopathy and vascular calcification after a single injection of moderate dose of CP $(10 \mathrm{mg} / \mathrm{Kg})$ followed by high Pi diet. No surgical skills are required to generate this model.

\section{Gender effect}

Epidemiologic observations showed more dramatic kidney damage in male AKI patients and higher risk of progression to CKD in male than female patients [44, 47, 62-64]. There are limited animal experiments to address the gender difference in $\mathrm{AKI}$ and $\mathrm{CKD}$. We showed higher plasma $\mathrm{Cr}$ and BUN, and lower $\mathrm{Cl}_{\mathrm{Cr}}$ in male mice than female mice after one time $\mathrm{CP}$ injection even after normalization of animal body weights. We also observed more renal function loss, higher cardiac hypertrophy, and worse mineral metabolism in male mice than female mice after $\mathrm{CP}$ injection and high $\mathrm{Pi}$ diet challenge. But we cannot conclude that gender accounts for faster progression to CKD in male than female since male mice had more severe acute kidney damage at the onset. Further experiment is required to reduce acute kidney damage in male by lower CP dose and compare decline rate of renal function between male and female mice when both have same trough $\mathrm{Cl}_{\mathrm{Cr}}$ at acute phase, which may allow us to examine if gender makes the difference in CKD progression. 
Table 5 Comparison of differences in responses to exogenous Klotho protein between male and female CKD mice fed with a high Pi diet

\begin{tabular}{|c|c|c|c|c|c|c|}
\hline & \multicolumn{3}{|l|}{ Vehicle } & \multicolumn{3}{|l|}{ Cisplatin } \\
\hline & Male & Female & $P$-value & Male & Female & $P$-value \\
\hline Animal number & 5 & 5 & & 4 & 5 & \\
\hline BUN (mg/dl) & $22.3 \pm 1.2$ & $20.9 \pm 1.1$ & $>0.05$ & $31.2 \pm 2.2$ & $22.9 \pm 1.5$ & $<0.01$ \\
\hline $\mathrm{Cr}(\mathrm{mg} / \mathrm{dl})$ & $0.14 \pm 0.03$ & $0.11 \pm 0.02$ & $>0.05$ & $0.27 \pm 0.03$ & $0.21 \pm 0.01$ & $<0.01$ \\
\hline $\mathrm{Cr}_{\mathrm{Cl}}(\mathrm{ml} / \mathrm{min} / 100 \mathrm{~g} \mathrm{BW})$ & $1.01 \pm 0.06$ & $0.94 \pm 0.05$ & 0.08 & $0.75 \pm 0.03$ & $0.85 \pm 0.04$ & $<0.05$ \\
\hline Plasma Pi (mg/dl) & $6.92 \pm 0.48$ & $6.67 \pm 0.31$ & $>0.05$ & $7.41 \pm 0.27$ & $6.38 \pm 0.21$ & $<0.01$ \\
\hline Plasma Ca (mg/dl) & $9.31 \pm 0.45$ & $9.23 \pm 0.32$ & $>0.05$ & $9.12 \pm 0.45$ & $9.19 \pm 0.32$ & $>0.05$ \\
\hline Plasma PTH (pg/ml) & $165 \pm 16$ & $147 \pm 10$ & $>0.05$ & $303 \pm 36$ & $290 \pm 19$ & $>0.05$ \\
\hline Plasma $1,25-(\mathrm{OH})_{2} \mathrm{D}_{3}(\mathrm{pg} / \mathrm{ml})$ & $78.2 \pm 6.4$ & $89.8 \pm 11.7$ & 0.087 & $27.1 \pm 2.7$ & $34.6 \pm 3.6$ & $<0.05$ \\
\hline Plasma FGF23 (pg/ml) & $155 \pm 78$ & $140 \pm 45$ & $>0.05$ & $1308 \pm 219$ & $883 \pm 102$ & $<0.01$ \\
\hline Heart weight/body weight $(\mathrm{mg} / \mathrm{g})$ & $5.13 \pm 0.29$ & $4.89 \pm 0.14$ & $>0.05$ & $5.23 \pm 0.39$ & $5.11 \pm 0.21$ & $>0.05$ \\
\hline
\end{tabular}

Data were presented as means \pm SD at 20 weeks. The statistical significance was analyzed by unpaired Student $t$-test $\alpha$ Klotho treatment prevents CKD progression, improves $\mathrm{Pi}$ metabolism, and cardiac hypertrophy in CKD more efficiently in male mice than female mice, suggesting that CKD male benefits more from Klotho treatment than CKD females. These findings are consistent with previous reports of transgenic male mice with overexpressing Klotho having prolonged lifespan compared to WT male mice, but transgenic female mice do not [65]. These results provide exciting evidence to support that Klotho protein might be highly promising strategy for CKD subjects.

\section{Age effect}

We showed that old mice had more severe kidney injury and cardiomyopathy after exposure to IRI followed by $2.0 \%$ Pi diet than young mice [10]. The current study further confirmed that the aging renders mice more susceptible to CP nephrotoxicity, which is in agreement with clinical observation [14]. Furthermore, older mice develop worse CVD in the CP nephrotoxicity model compared to young mice. The molecular mechanisms of how aging affects kidney and CVD remain to be established and are likely complicated. Factors such as low renal and circulating $\alpha$ Klotho [10], oxidative stress [66], endothelial dysfunction [67, 68], and low autophagy [69] may particulate in contributing to poor renal and cardiovascular outcome in aged mice.

\section{aKlotho effect on the severity of CP-induced nephrotoxicity}

$\alpha$ Klotho deficiency is a feature of CKD and is a critical pathogenic intermediate for CKD progression and CVD development in CKD [8-11, 35, 41, 70, 71]. Low $\alpha$ Klotho levels in the kidney and the circulation were not only present at acute period of $\mathrm{CP}$ nephrotoxicity, but persisted way beyond the apparent "recovery" of plasma Cr. CKD mice had high plasma Pi, PTH, and FGF23, as well as low 1,25$(\mathrm{OH})_{2}$ vitamin $\mathrm{D}_{3}$, all of them might be contributors to Klotho deficiency. As we previously showed the effect of $\alpha$ Klotho on the IRI model $[8,11], \alpha$ Klotho supplementation post-CP injection was effective in the retardation of CKD progression, as well as attenuation of uremic cardiomyopathy and vascular calcification, confirming the efficacy of $\alpha$ Klotho treatment in the CP-induced CKD model fed with high Pi diet.

In conclusion, $\mathrm{CP}$ leads to not only acute nephrotoxicity$\mathrm{AKI}$, and it causes AKI-to-CKD transition when coupled with high dietary phosphate. CKD rodents have disturbed mineral metabolism and uremic cardiovasculopathy. It is a technically easy and reproducible model that can be utilized for the study of AKI-to-CKD transition and CKDassociated complications, and test therapeutic maneuvers.

Acknowledgements These studies were supported by the National Institutes of Health (NIDDK-R01-DK091392, NIDDK-R01DK092461, NIDDK-R01-DK092461-6A1), the George O'Brien Kidney Research Center at University of Texas Southwestern Medical Center (NIDDK-P30-DK079328), the Charles and Jane Pak Center Innovative Research Support, the Pak-Seldin Center for Metabolic and Clinical Research, and C. Y Pak Foundation. The authors particularly thank Ms. Ao Bian, Ms. Han Cho, and Ms. Jean Paek for expert technical assistance.

\section{Compliance with ethical standards}

Conflict of interest The authors declare that they have no conflict of interest.

\section{References}

1. Cerda J, Lameire N, Eggers P, et al. Epidemiology of acute kidney injury. Clin J Am Soc Nephrol. 2008;3:881-6.

2. Susantitaphong P, Cruz DN, Cerda J, et al. World incidence of AKI: a meta-analysis. Clin J Am Soc Nephrol. 2013;8:1482-93. 
3. Bouchard J, Mehta RL. Acute kidney injury in western countries. Kidney Dis. 2016;2:103-10.

4. Case J, Khan S, Khalid R, Khan A. Epidemiology of acute kidney injury in the intensive care unit. Crit Care Res Pract. 2013;2013: 479730.

5. Ali T, Khan I, Simpson W, et al. Incidence and outcomes in acute kidney injury: a comprehensive population-based study. J Am Soc Nephrol. 2007;18:1292-8.

6. Hsu CY. Yes, AKI truly leads to CKD. J Am Soc Nephrol. 2012;23:967-9.

7. Bucaloiu ID, Kirchner HL, Norfolk ER, Hartle JE 2nd, Perkins RM. Increased risk of death and de novo chronic kidney disease following reversible acute kidney injury. Kidney Int. 2012;81:477-85.

8. Shi M, Flores B, Gillings N, et al. AlphaKlotho mitigates progression of AKI to CKD through activation of autophagy. J Am Soc Nephrol. 2016;27:2331-45.

9. Hu MC, Shi M, Zhang J, et al. Klotho deficiency causes vascular calcification in chronic kidney disease. J Am Soc Nephrol. 2011;22:124-36.

10. Hu MC, Shi M, Cho HJ, et al. Klotho and phosphate are modulators of pathologic uremic cardiac remodeling. J Am Soc Nephrol. 2015;26:1290-302.

11. Hu MC, Shi M, Gillings N, et al. Recombinant alpha-Klotho may be prophylactic and therapeutic for acute to chronic kidney disease progression and uremic cardiomyopathy. Kidney Int. 2017;91: 1104-14.

12. Faught LN, Greff MJ, Rieder MJ, Koren G. Drug-induced acute kidney injury in children. Br J Clin Pharmacol. 2015;80: 901-9.

13. Sato K, Watanabe S, Ohtsubo A, et al. Nephrotoxicity of cisplatin combination chemotherapy in thoracic malignancy patients with CKD risk factors. BMC Cancer. 2016;16:222.

14. Latcha S, Jaimes EA, Patil S, et al. Long-term renal outcomes after cisplatin treatment. Clin J Am Soc Nephrol. 2016;11:1173-9.

15. Walker EM Jr., Gale GR. Methods of reduction of cisplatin nephrotoxicity. Ann Clin Lab Sci. 1981;11:397-410.

16. Ravichandran K, Wang Q, Ozkok A, et al. CD4 T cell knockout does not protect against kidney injury and worsens cancer. J Mol Med. 2016;94:443-55.

17. Katagiri D, Hamasaki Y, Doi K, et al. Interstitial renal fibrosis due to multiple cisplatin treatments is ameliorated by semicarbazidesensitive amine oxidase inhibition. Kidney Int. 2016;89:374-85.

18. Gonzalez R, Romay C, Borrego A, et al. Lipid peroxides and antioxidant enzymes in cisplatin-induced chronic nephrotoxicity in rats. Mediat Inflamm. 2005;2005:139-43.

19. Torres R, Velazquez H, Chang JJ, et al. Three-dimensional morphology by multiphoton microscopy with clearing in a model of cisplatin-induced CKD. J Am Soc Nephrol. 2016;27:1102-12.

20. Sharp CN, Doll MA, Dupre TV, et al. Repeated administration of low-dose cisplatin in mice induces fibrosis. Am J Physiol Ren Physiol. 2016;310:F560-8.

21. Sharp CN, Siskind LJ. Developing better mouse models to study cisplatin-induced kidney injury. Am J Physiol Ren Physiol. 2017;313:F835-F41.

22. Hu MC, Shi M, Zhang J, et al. Klotho deficiency is an early biomarker of renal ischemia-reperfusion injury and its replacement is protective. Kidney Int. 2010;78:1240-51.

23. Hu MC, Shi M, Zhang J, et al. Klotho: a novel phosphaturic substance acting as an autocrine enzyme in the renal proximal tubule. FASEB J. 2010;24:3438-50.

24. Panesso MC, Shi M, Cho HJ, et al. Klotho has dual protective effects on cisplatin-induced acute kidney injury. Kidney Int. 2014;85:855-70

25. Barker SL, Pastor J, Carranza D, et al. The demonstration of alphaKlotho deficiency in human chronic kidney disease with a novel synthetic antibody. Nephrol Dial Transplant. 2015;30: 223-33.

26. Moghal NE, Ferreira MA, Howie AJ, et al. The late histologic findings in diarrhea-associated hemolytic uremic syndrome. J Pediatr. 1998;133:220-3.

27. $\mathrm{Hu} \mathrm{MC}$, Moe OW. Klotho as a potential biomarker and therapy for acute kidney injury. Nat Rev Nephrol. 2012;8:423-9.

28. Faul C, Amaral AP, Oskouei B, et al. FGF23 induces left ventricular hypertrophy. J Clin Invest. 2011;121:4393-408.

29. Kramann R, Tanaka M, Humphreys BD. Fluorescence microangiography for quantitative assessment of peritubular capillary changes after AKI in mice. J Am Soc Nephrol. 2014;25:1924-31.

30. Nematbakhsh M, Ebrahimian S, Tooyserkani M, et al. Gender difference in cisplatin-induced nephrotoxicity in a rat model: greater intensity of damage in male than female. Nephrourol Mon. 2013;5:818-21.

31. Zhou L, Li Y, Zhou D, Tan RJ, Liu Y. Loss of Klotho contributes to kidney injury by derepression of Wnt/beta-catenin signaling. J Am Soc Nephrol. 2013;24:771-85.

32. Appenroth D, Braunlich H. Age differences in cisplatinum nephrotoxicity. Toxicology. 1984;32:343-53.

33. Hrushesky WJ, Shimp W, Kennedy BJ. Lack of age-dependent cisplatin nephrotoxicity. Am J Med. 1984;76:579-84.

34. Kanbay M, Goldsmith D, Akcay A, Covic A. Phosphate-the silent stealthy cardiorenal culprit in all stages of chronic kidney disease: a systematic review. Blood Purif. 2009;27:220-30.

35. Foley RN. Phosphate levels and cardiovascular disease in the general population. Clin J Am Soc Nephrol. 2009;4:1136-9.

36. Striker GE, Grosjean F, Vlassara H. Phosphate and CVD: it's all in what's on the table. Arterioscler Thromb Vasc Biol. 2011;31: 1951-2.

37. Toussaint ND, Pedagogos E, Tan SJ, et al. Phosphate in early chronic kidney disease: associations with clinical outcomes and a target to reduce cardiovascular risk. Nephrology. 2012;17:433-44.

38. Li JW, Xu C, Fan Y, Wang Y, Xiao YB. Can serum levels of alkaline phosphatase and phosphate predict cardiovascular diseases and total mortality in individuals with preserved renal function? A systemic review and meta-analysis. PLoS ONE. 2014;9:e102276.

39. Isakova T, Ix JH, Sprague SM, et al. Rationale and approaches to phosphate and fibroblast growth factor 23 reduction in CKD. J Am Soc Nephrol. 2015;26:2328-39.

40. Jozefacki A, White CA, Shobeiri NS, et al. Phosphate excretion is decreased in older cardiac patients with normal kidney function: an emerging dietary risk factor? Appl Physiol Nutr Metab. 2016;41:452-5.

41. Shen ZJ, Hu J, Shiizaki K, Kuro-o M, Malter JS. Phosphateinduced renal fibrosis requires the prolyl isomerase pin1. PLoS ONE. 2016;11:e0150093.

42. Vervloet MG, Sezer S, Massy ZA, et al. The role of phosphate in kidney disease. Nat Rev Nephrol. 2017;13:27-38.

43. Bian A, Xing C, Hu MC. Alpha Klotho and phosphate homeostasis. J Endocrinol Invest. 2014;37:1121-6.

44. Kollerits B, Fliser D, Heid IM, et al. Gender-specific association of adiponectin as a predictor of progression of chronic kidney disease: the mild to moderate kidney disease study. Kidney Int. 2007;71:1279-86.

45. Diwan V, Small D, Kauter K, Gobe GC, Brown L. Gender differences in adenine-induced chronic kidney disease and cardiovascular complications in rats. Am J Physiol Ren Physiol. 2014;307:F1169-78.

46. Cobo G, Hecking M, Port FK, et al. Sex and gender differences in chronic kidney disease: progression to end-stage renal disease and haemodialysis. Clin Sci. 2016;130:1147-63.

47. Chang PY, Chien LN, Lin YF, et al. Risk factors of gender for renal progression in patients with early chronic kidney disease. Medicine. 2016;95:e4203. 
48. Carrero JJ, Hecking M, Ulasi I, Sola L, Thomas B. Chronic kidney disease, gender, and access to care: a global perspective. Semin Nephrol. 2017;37:296-308.

49. Jones TW, Chopra S, Kaufman JS, Flamenbaum W, Trump BF. Cis-diamminedichloroplatinum (II)-induced acute renal failure in the rat. Correlation of structural and functional alterations. Lab Invest. 1985;52:363-74.

50. Chopra S, Kaufman JS, Jones TW, et al. Cis-diamminedichlorplatinuminduced acute renal failure in the rat. Kidney Int. 1982;21:54-64.

51. Bhatt K, Zhou L, Mi QS, et al. MicroRNA-34a is induced via p53 during cisplatin nephrotoxicity and contributes to cell survival. Mol Med. 2010;16:409-16.

52. Jiang M, Dong Z. Self-eating for death or survival during cisplatin nephrotoxicity? Clin Exp Nephrol. 2010;14:516-7.

53. Yang Y, Liu H, Liu F, Dong Z. Mitochondrial dysregulation and protection in cisplatin nephrotoxicity. Arch Toxicol. 2014;88: 1249-56.

54. Safirstein R, Miller P, Dikman S, Lyman N, Shapiro C. Cisplatin nephrotoxicity in rats: defect in papillary hypertonicity. Am J Physiol. 1981;241:F175-85.

55. Nakada J, Machida T, Endou H. Nephrotoxicity of cisplatin in rats. Dev Toxicol Environ Sci. 1986;14:179-82.

56. Trujillo J, Molina-Jijon E, Medina-Campos ON, et al. Renal tight junction proteins are decreased in cisplatin-induced nephrotoxicity in rats. Toxicol Mech Methods. 2014;24:520-8.

57. Campbell AB, Kalman SM, Jacobs C. Plasma platinum levels: relationship to cisplatin dose and nephrotoxicity. Cancer Treat Rep. 1983;67:169-72.

58. Mulder RL, Knijnenburg SL, Geskus RB, et al. Glomerular function time trends in long-term survivors of childhood cancer: a longitudinal study. Cancer Epidemiol Biomark Prev. 2013;22: 1736-46.

59. Dekkers IA, Blijdorp K, Cransberg K, et al. Long-term nephrotoxicity in adult survivors of childhood cancer. Clin J Am Soc Nephrol. 2013;8:922-9.
60. Marcussen N. Atubular glomeruli in cisplatin-induced chronic interstitial nephropathy. Exp Stereol Investig APMIS. 1990;98:1087-97.

61. Okada A, Fukushima K, Fujita M, et al. Alterations in cisplatin pharmacokinetics and its acute/sub-chronic kidney injury over multiple cycles of cisplatin treatment in rats. Biol Pharm Bull. 2017;40:1948-55.

62. Reyes D, Lew SQ, Kimmel PL. Gender differences in hypertension and kidney disease. Med Clin North Am. 2005;89:613-30.

63. Kummer S, von Gersdorff G, Kemper MJ, Oh J. The influence of gender and sexual hormones on incidence and outcome of chronic kidney disease. Pediatr Nephrol. 2012;27:1213-9.

64. Eriksen BO, Ingebretsen OC. The progression of chronic kidney disease: a 10-year population-based study of the effects of gender and age. Kidney Int. 2006;69:375-82.

65. Kurosu H, Yamamoto M, Clark JD, et al. Suppression of aging in mice by the hormone Klotho. Science. 2005;309:1829-33.

66. Fan LM, Cahill-Smith S, Geng L, et al. Aging-associated metabolic disorder induces Nox2 activation and oxidative damage of endothelial function. Free Radic Biol Med. 2017;108: 940-51.

67. Wulfert FM, van Meurs M, Kurniati NF, et al. Age-dependent role of microvascular endothelial and polymorphonuclear cells in lipopolysaccharide-induced acute kidney injury. Anesthesiology. 2012;117:126-36.

68. Wang X, Bonventre JV, Parrish AR. The aging kidney: increased susceptibility to nephrotoxicity. Int J Mol Sci. 2014;15:15358-76.

69. Zhou J, Chong SY, Lim A, et al. Changes in macroautophagy, chaperone-mediated autophagy, and mitochondrial metabolism in murine skeletal and cardiac muscle during aging. Aging (Albany NY). 2017;9:583-99.

70. Lu X, Hu MC. Klotho/FGF23 axis in chronic kidney disease and cardiovascular disease. Kidney Dis. 2017;3:15-23.

71. Neyra JA, Hu MC. Potential application of klotho in human chronic kidney disease. Bone. 2017;100:41-9. 